Document downloaded from:

http://hdl.handle.net/10251/68915

This paper must be cited as:

Adamova, G.; Gardas, RL.; Nieuwenhuyzen, M.; Vaca Puga, A.; Rebelo, LPN.; Robertson, AJ.; Seddon, KR. (2012). Alkyltributylphosphonium chloride ionic liquids: synthesis, physicochemical properties and crystal structure. Dalton Transactions. 41(27):8316-8332. doi:10.1039/c1dt10466g.

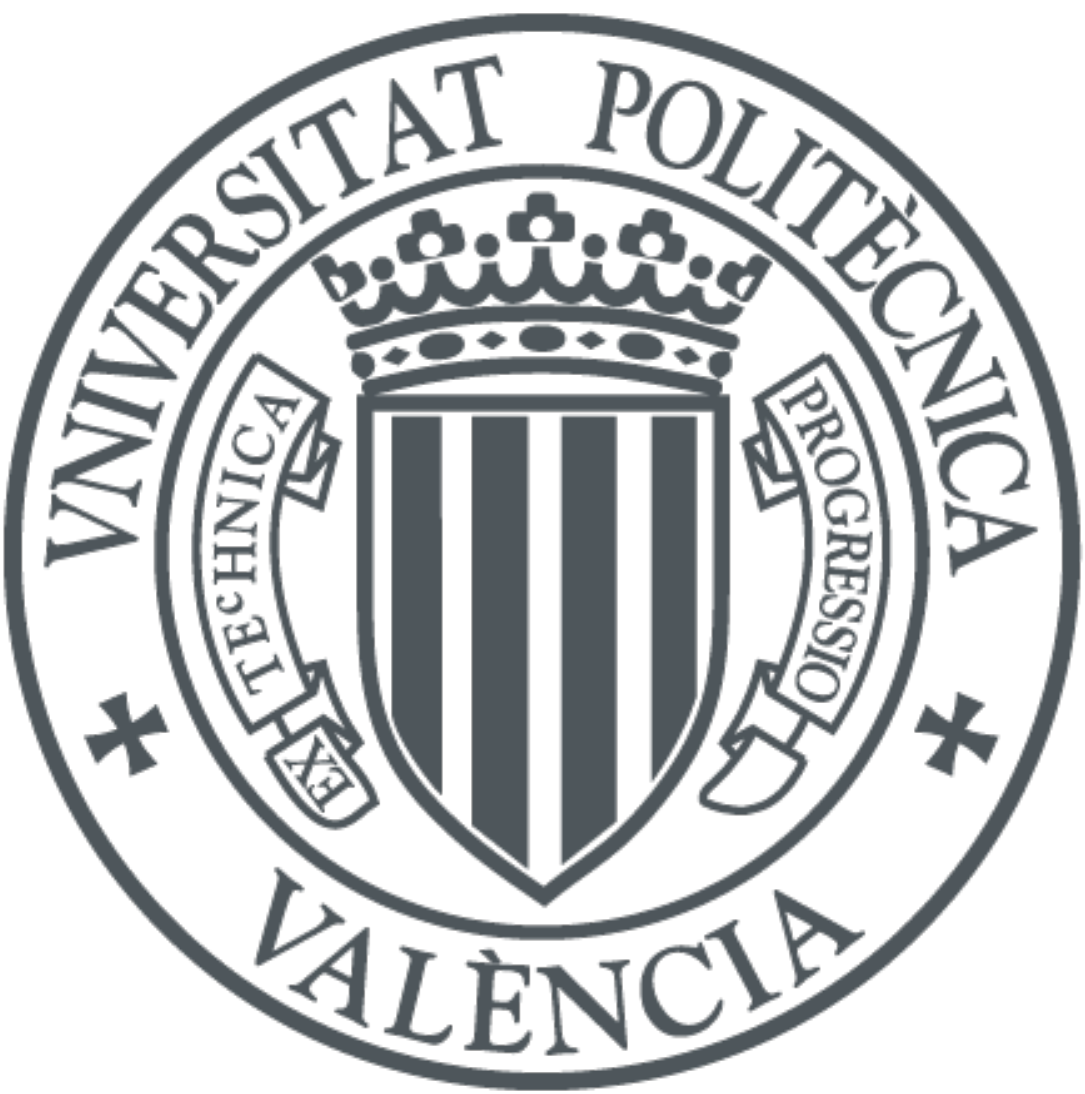

The final publication is available at

http://dx.doi.org/10.1039/c1dt10466g

Copyright Royal Society of Chemistry

Additional Information 


\title{
Alkyltributylphosphonium chloride ionic liquids: synthesis, physicochemical properties and crystal structure
}

\author{
Gabriela Adamová, ${ }^{a}$ Ramesh L. Gardas, ${ }^{a, b}$ Mark Nieuwenhuyzen, ${ }^{a}$ Alberto V. Puga, ${ }^{a}$ \\ Luìs Paulo N. Rebelo, ${ }^{c}$ Allan J. Robertson ${ }^{d}$ and Kenneth R. Seddon ${ }^{a, c}$ \\ ${ }_{5}$ Received (in $\left.X X X, X X X\right) X$ th $X X X X X X X X X 20 X X$, Accepted $X$ th $X X X X X X X X X 20 X X$ \\ DOI: $10.1039 / b 000000 x$
}

A series of alkyltributylphosphonium chloride ionic liquids, prepared from tributylphosphine and the respective 1-chloroalkane, $\mathrm{C}_{n} \mathrm{H}_{2 n+1} \mathrm{Cl}$ (where $n=1,2,3,4,5,6,7,8,9,10,12$ or 14) is reported. This work is a continuation of an extended series of tetralkylphosphonium ionic liquids, where the focus is on

10 the variability of $n$ and its impact on the physical properties, such as melting points / glass transitions, thermal stability, density and viscosity. Experimental density and viscosity data were interpreted using QPSR and group contribution methods and the crystal structure of propyl(tributyl)phosphonium chloride is detailed.

\section{Introduction}

15 Tetraalkylphosphonium ionic liquids are a readily available family of ionic liquids that, in many applications, offer superior properties when compared to nitrogen-based ionic liquids. ${ }^{1-6}$ Applications investigated in recent years include their use as extraction and synthetic solvents, electrolytes in batteries, 20 corrosion protection, or in petrochemical applications. ${ }^{1}$

The most attention in the literature has been given to the $\left[\mathrm{P}_{6} 66_{14}\right]^{+}$cation, ${ }^{7-10}$ as this is commercially available with a range of different anions, and relatively cheap. However, there are very few systematic studies of the physicochemical and thermal 25 properties of ionic liquids prepared with different phosphonium cations. As a detailed systematic analysis of fundamental properties of tetraalkylphosphonium ionic liquids is necessary for future application of these compounds, we report here the properties of a related series of hydrophilic ionic liquids, $30\left[\mathrm{P}_{444 n}\right] \mathrm{Cl}$, where $n=1-8,10,12$ or 14 (see Figure 1), to complement data recently published from our group relating to the hydrophobic $\left[\mathrm{P} 88_{8}{ }_{n}\right] \mathrm{Cl} .^{11}$

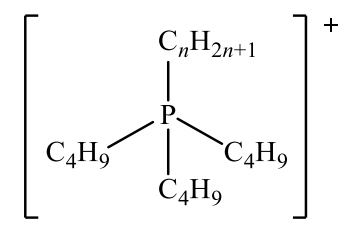

Fig. 1 The structure of the alkyltributylphosphonium cation, $\left[\mathrm{P}_{444 n}\right]^{+}$, 35 where $n=1,2,3,4,5,6,7,8,10,12$ or 14 .

The variation of length in the variable alkyl chain has been studied with respect to its effect on the density, viscosity, melting points/glass transitions and thermal stability. Related studies based on the alkyltrihexylphosphonium cations will be published 40 shortly. ${ }^{11,12}$ Although there are a few recent papers reporting tetrabutylphosphonium salts with different anions, the most interesting ones feature anions derived from amino acids. ${ }^{13-15}$ However, reports of alkyltributylphosphonium halides date back the 1980s, when Knifton (a Texaco chemist) published a 45 fascinating series of patents and papers in which the "molten

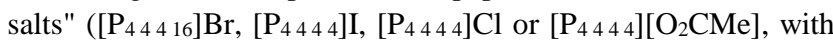
the cynosure on $\left[\mathrm{P}_{4444}\right] \mathrm{Br}$ ) were used as the basis for the hydroformylation of internal olefins in the presence of a range of ruthenium catalysts. ${ }^{16,17-26}$ Alkyltributylphosphonium halides 50 were successfully applied in late $80 \mathrm{~s}$ as a biocides ${ }^{27}$ or as compounds with microbiological activity for water treatment. ${ }^{28}$ The series presented here has also been tested for toxicity with respect to a specific group of fungi, by Pereira's group in Portugal, and these data will be reported elsewhere. ${ }^{29}$

55 Despite the impact of Knifton's studies, it was not until 1990 that tributylphosphine was produced on a large commercial scale. Since that time, not only have tetrabutylphosphonium chloride and bromide become available on the multi-ton scale, but so have many trialkylphosphines. ${ }^{7}$ This manuscript illuminates the 60 versatility and practical applicability of ionic liquids derived from tributylphosphine by making available for the first time a systematic study of their physical and structural properties and contrasts them with those of related tetraalkylammonium salts.

\section{Experimental}

\section{Instrumental}

Autoclave. The miniclave drive manufactured by Büchi Glas Uster (Switzerland) was purchased from Ken Kimbel \& Co. Ltd. (United Kingdom). The autoclave consists of a glass reactor with nominal volume $200 \mathrm{~cm}^{3}$; holder for glass reactor with stainless 70 steel anti-splinter cage; insert ring; cover plate with 6 welded-in $1 / 4$ " Swagelok connections, welded on bmd 075 magnetic drive; O-ring seal; union nut and holding rod. The magnetic coupling 
(bmd 075) is combined with the cyclone 075 (0-2500 rpm) equipped with an electric motor, into a hermetically sealed unit. The controller is equipped with a remote control input for external speed adjustment. The stationary housing of the 5 magnetic drive and the cover plate are welded together and built as one common unit. The cover plate contains pressure relief valve, platinum resistance thermometer ( $\mathrm{Pt} \mathrm{100),} \mathrm{gas} \mathrm{inlet} \mathrm{tube,}$ pressure gauge and an inlet/outlet tube. The maximum temperature is $250{ }^{\circ} \mathrm{C}$ and maximum pressure is 10 bar.

${ }_{10}$ Microwave. MicroSYNTH microwave used was manufactured by Milestone (Italy) as the single-mode set up with $20 \mathrm{~cm}^{3}$ volume vial placed in the TMF safety shield vessel, closed by TMF screw cap and located in the microwave cavity (43 1) at the position with the highest energy intensity allowing rapid heating.

15 Reaction temperature control is provided by an IR sensor (max. $250{ }^{\circ} \mathrm{C}$ ), monitoring the outside surface temperature of the vessel, mounted in the sidewall of the cavity, about $5 \mathrm{~cm}$ above the bottom and fiber-optic sensor ( $\max .300{ }^{\circ} \mathrm{C}$ ) immersed inside of the vessel. A pneumatic pressure sensor (max. 55 bar) placed 20 inside of the vessel monitors the vapour concentration and overall pressure. An additional sensor monitors the pressure inside of the cavity. Post-reaction cooling of the reaction mixture is achieved by a constant airflow $\left(1.8 \mathrm{~m}^{3} \mathrm{~min}^{-1}\right)$ through the cavity and a stream of compressed air. The MicroSYNTH reaction system is 25 monitored via an external control terminal with a touch screen display utilising the EasyControl 640 software package. The run can be controlled either by temperature, pressure or microwave output (max. $1000 \mathrm{~W})$. The software enables on-line modifications of any method parameter and the reaction process 30 is monitored by an appropriate graphical interface. Agitation is achieved by magnetic stirring (max. $400 \mathrm{rpm}$ ) controlled by software.

NMR spectroscopy. All NMR spectra were recorded on a Bruker Avance spectrometer DPX 300 at $21{ }^{\circ} \mathrm{C}$, using deuteriated 35 propanone as solvent $\left(10-20 \mathrm{mM}\right.$ solutions for ${ }^{1} \mathrm{H}$ and ${ }^{31} \mathrm{P} \mathrm{NMR}$ spectroscopy; 30-35 mM solutions for ${ }^{13} \mathrm{C}$ NMR spectroscopy), referred to TMS for ${ }^{1} \mathrm{H}$ and ${ }^{13} \mathrm{C}$ NMR spectra and $85 \% \mathrm{H}_{3} \mathrm{PO}_{4}$ for ${ }^{31} \mathrm{P}$ NMR spectra.

Mass spectrometry. Most samples were analysed by fast atom 40 bombardment (FAB) spectrometry, performed on with VGAutospec (Fisons Instruments) in a positive ion mode. Microanalysis. Elemental carbon and hydrogen contents (wt\%) were analysed using a Perkin-Elmer Series II CHNS/O 2400 $\mathrm{CHN}$ Elemental Analyser, and provided analysis within $\pm 0.3 \mathrm{wt} \%$ 45 error. Halide content was determined by dioxygen flask, combustion followed by halide titration with aquous mercury(II) nitrate, using a dicarbazide indicator.

Water content. Water content was determined using a Cou-Lo Compact (version 08.05) Karl Fischer titrator, and titration 50 solutions from Riedel-de-Haën. Ionic liquids were tested immediately after drying under high vacuum for $48 \mathrm{~h}$, and the water content was below $750 \mathrm{ppm}$ for all samples.

Differential scanning calorimetry (DSC). The melting points and glass transitions of the compounds were measured by DSC, 55 using a TA Instruments Modulated DSC Q 2000 V24.4 Build 116 with refrigerated cooling system RCS 90 capable of controlling the temperature down to $220 \mathrm{~K}$. Dry dinitrogen gas was purged through the DSC cell with a flow rate of $c a .20 \mathrm{~cm}^{3} \mathrm{~min}^{-1}$. All samples, due to their hygroscopic character, were prepared in a 60 glove box, using Tzero hermetic platinum pans to avoid any contact with air and measured under the same conditions (standard heating and cooling ramp of $5 \mathrm{~K} \mathrm{~min}^{-1}$ over five cycles). The melting point is taken as the onset of an endothermic peak on heating and the glass transition temperature is taken as 65 the midpoint of a small heat flow change on heating from the amorphous glass state to a liquid state.

Thermogravimetric analysis (TGA). Decomposition temperature measurements were performed in a TA Instruments Q50 thermogravimetric analyser. The samples were measured in 70 platinum pans, at a heating rate of $10 \mathrm{~K} \mathrm{~min}^{-1}$, in a dynamic mode, under dinitrogen atmosphere. The onset of the weight loss in each thermogram was used as a measure of decomposition temperature (see discussion). The sample size was typically between 7 and $10 \mathrm{mg}$ and sample preparation was similar to that 75 described for the DSC measurments.

Density measurements. Density was measured with an Anton Paar vibrating tube densimeter, model DMA 4500, operating at atmospheric pressure and within the temperature range 273 to $363 \mathrm{~K}$. The internal calibration of the instrument was confirmed 80 by measuring densities of atmospheric air and doubly distilled water, according to the recommendations of the manufacturer. The DMA 4500 cell was embedded in a metallic block, the temperature of which was controlled by several Peltier units. This arrangement enabled a temperature stability better than $\pm 2 \mathrm{mK}$.

85 All ionic liquids used in density determinations were degassed under vacuum and moderate temperature conditions for periods longer than $48 \mathrm{~h}$ and were injected into the densimeter into the densimeter immediately after cooling, using non-lubricated disposable syringes.

${ }_{90}$ Viscosity measurements. The viscosity was determined using an AMVn microviscometer, Anton Paar, that allows measurements from 273 to $363 \mathrm{~K}$ at atmospheric pressure, and over a wide viscosity range $(0.3$ to $20000 \mathrm{mPa} \mathrm{s})$. A glass capillary with 4 $\mathrm{mm}$ internal diameter with a $3 \mathrm{~mm}$ gold/tungsten ball (placed 95 inside the capillary) with density $15 \mathrm{~g} \mathrm{~cm}^{-3}$ was chosen for this study and an extension of runtime up to $1000 \mathrm{~s}$ was required due to the high viscosity of each sample. Temperature was maintained constant to within $\pm 0.01 \mathrm{~K}$ by a capillary block with in-built Peltier elements. Since these ionic liquids were extremely 100 hygroscopic, the capillary was always charged in the glove box. The capillary/ball system was calibrated with standard viscosity oil (1 Pa s) from PRA. Viscosity measurements were performed in steps of $10 \mathrm{~K}$ from $293 \mathrm{~K}$ up to $363 \mathrm{~K}$ for all ionic liquid samples for which a sufficient amount $\left(c a .3 .5 \mathrm{~cm}^{3}\right)$ was 105 available. Each sample was measured ten times in order to check reproducibility.

X-ray analysis. Crystal data for $\left[\mathrm{P}_{44} 4_{3}\right] \mathrm{Cl}$ were collected using a Bruker kappaCCD diffractometer with graphite monochromated Mo- $K_{\alpha}$ radiation at $c a .150 \mathrm{~K}$ in a dinitrogen stream. Lorentz and 110 polarisation corrections were applied. The structure was solved by direct methods and the non-hydrogen atoms were refined with anisotropic thermal parameters. Hydrogen-atom positions were added at idealised positions and a riding model with fixed thermal parameters $\left(U_{\mathrm{ij}}=1.2 U_{\mathrm{eq}}\right.$ for the atom to which they are bonded 115 (1.5 for methyl)), was used for subsequent refinements. The nature of the disorder in the cation conformations required that 
restraints be included on all of the $\mathrm{P}-\mathrm{C}, \mathrm{C}-\mathrm{C}$ and $\mathrm{C}-\mathrm{H}$ bond lengths and bond angles to provide a chemically sensible model for the cations. The function minimised was $\Sigma\left[w\left(\left|F_{0}\right|^{2}-\left|F_{\mathrm{c}}\right|^{2}\right)\right]$ with reflection weights $w^{-1}=\left[\sigma^{2}\left|F_{0}\right|^{2}+\left(g_{1} P\right)^{2}+\left(g_{2} P\right)\right]$ where ${ }_{5} P=\left[\max \left|F_{0}\right|^{2}+2\left|F_{\mathrm{c}}\right|^{2}\right] / 3$. The SHELXTL package ${ }^{30}$ was used for structure solution and refinement.

Search procedures in the Cambridge Structural Database (CSD) were carried out using ConQuest 1.13. ${ }^{31,} 32$ The CSD (version 5.32, updated November 2010) was examined using the 10 following criteria: 3D coordinates determined, with no errors and no powder structures.

Single crystals of $\mathrm{C}_{15} \mathrm{H}_{34} \mathrm{ClP}$ were grown by slow crystallisation from the melt at $70{ }^{\circ} \mathrm{C}$. Crystal data for $\left[\mathrm{P}_{44_{4}}\right] \mathrm{Cl}$. $\mathrm{C}_{15} \mathrm{H}_{34} \mathrm{ClP}, \quad T=150 \mathrm{~K}, \quad$ monoclinic, $P 2_{1} / \mathrm{c}, \quad a=9.9996(5)$, $15 b=13.4309(12), \quad c=13.3481(10) \AA, \quad \beta=91.331(5)^{\circ}, \quad V=$ 1792.2(2) $\AA^{3}, \quad Z=4, \quad D_{\mathrm{c}}=1.041 \mathrm{~g} \mathrm{~cm}^{-3}, \quad$ reflections collected/unique $=7858 / 2329 \quad\left(R_{\text {int }}=0.0821\right), \quad \mu=2.565 \mathrm{~mm}^{-1}$, $S=1.065, R_{1}=0.0821(I>2 \sigma), w R\left(F_{2}\right)=0.2539$ (all data).

Glove box. All ionic liquids studied here were handled in a 20 dinitrogen-filled glove box (MBraun LabMaster dp; 0.1 ppm $<\mathrm{O}_{2}$ and $\mathrm{H}_{2} \mathrm{O}$ ) immediately after drying, and stored there until used.

\section{Materials}

The phosphonium ionic liquids presented in this study were synthesised following the procedures described in the next 25 section. Chloromethane $(\geq 99.5 \%)$, chloroethane $(\geq 99.7 \%)$, 1chloropropane (98\%), 1-chloropentane (99\%), 1-chlorohexane (99\%), 1-chloroheptane (99\%), 1-chlorooctane (99\%), 1- chlorononane (98\%), 1-chlorodecane (98\%), 1-chlorododecane (98\%), were all purchased from Aldrich and used as received. 30 Tributylphosphine $\left(50 \%\right.$ solution in toluene, $\left.\rho=0.82 \mathrm{~g} \mathrm{~cm}^{-3}\right)$, Tributyl(methyl)phosphonium methylcarbonate (75\% solution in methanol), $\left[\mathrm{P}_{4444}\right] \mathrm{Cl}$ and $\left[\mathrm{P}_{44414}\right] \mathrm{Cl}$ were supplied by Cytec Industries, Canada.

\section{${ }_{35}$ Synthetic procedures}

Four different techniques were used to synthesise alkyltributylphosphonium chlorides. $\left[\mathrm{P}_{44_{1}}\right] \mathrm{Cl}$ was synthesised by a neutralisation reaction of methanolic 40 tributylmethylphosphonium methylcarbonate with concentrated aqueous hydrochloric acid. An autoclave was used for the reaction with chloroethane. Synthesis of $\left[\mathrm{P}_{44_{4}}\right] \mathrm{Cl}$ which involved chloropropane was performed in a microwave reactor, and the remaining compounds requiring low-volatility 45 chloroalkanes were synthesised via thermal reflux. Glassware used was charged with starting materials in an M-size Atmosbag ${ }^{\circledR}$ (purchased from Sigma Aldrich) which was filled with dinitrogen, in order to provide an inert atmosphere and avoid potential oxidation of the alkylphosphines to alkylphosphine 50 oxides. Details of individual syntheses are given in Table 1, elemental analytical results are reported in Table 2 . In all cases reactions were characterised by ${ }^{31} \mathrm{P},{ }^{13} \mathrm{C},{ }^{1} \mathrm{H}$ NMR (Tables 3 and 4; Figure 2) and by mass spectrometry (Table 2) prior to purification.

55 Table 1 Masses of reagents $(m)$, reaction conditions for synthesis, yield, appearance and water content of $\left[\mathrm{P}_{444 n}\right] \mathrm{Cl}$ ionic liquids, masses and volumes of $\mathrm{P}_{444}$ reported at pure state $\left(\mathrm{P}_{44}\right.$ was supplied in a $50 \%$ solution in toluene).

\begin{tabular}{|c|c|c|c|c|c|c|c|c|c|c|c|}
\hline \multirow[b]{2}{*}{$n$} & \multicolumn{2}{|c|}{$\mathbf{P}_{444}$} & \multicolumn{3}{|c|}{$\mathrm{C}_{n} \mathrm{H}_{2 \mathrm{n}+1} \mathrm{Cl}$} & \multirow[b]{2}{*}{$\mathrm{T} /{ }^{\circ} \mathrm{C}$} & \multirow[b]{2}{*}{$t / \mathbf{h}$} & \multirow[b]{2}{*}{ Yield/\% } & \multirow[b]{2}{*}{ Colour } & \multirow[b]{2}{*}{ State $^{c}$} & \multirow[b]{2}{*}{$\mathrm{H}_{2} \mathrm{O} / \mathrm{ppm}$} \\
\hline & $V / \mathrm{cm}^{3}$ & $\mathrm{~m} / \mathrm{g}$ & $V / \mathrm{cm}^{3}$ & $\mathrm{~m} / \mathrm{g}$ & $\rho / \mathrm{g} \mathrm{cm}^{-3} *$ & & & & & & \\
\hline 2 & 48.80 & 40 & 32.70 & 30 & 0.918 & $140^{\mathrm{a}}$ & $4.5^{\mathrm{a}}$ & 88 & Pale yellow & $\mathrm{s}$ & 648 \\
\hline 3 & 7.32 & 6 & 2.90 & 2.60 & 0.892 & $180^{\mathrm{b}}$ & $0.5^{\mathrm{b}}$ & 93 & Pale yellow & $\mathrm{s}$ & 622 \\
\hline 4 & - & - & - & - & - & - & - & - & Pale yellow & $\mathrm{s}$ & 593 \\
\hline 5 & 14.60 & 12 & 7.90 & 6.95 & 0.882 & 145 & 12 & 90 & White & $\mathrm{s}$ & 543 \\
\hline 6 & 14.60 & 12 & 8.94 & 7.90 & 0.879 & 145 & 12 & 92 & Colourless & 1 & 450 \\
\hline 7 & 14.60 & 12 & 9.96 & 8.80 & 0.881 & 145 & 14 & 94 & White & $\mathrm{s}$ & 531 \\
\hline 8 & 14.60 & 12 & 11.04 & 9.70 & 0.875 & 145 & 14 & 92 & Colourless & 1 & 447 \\
\hline 10 & 14.60 & 12 & 13.23 & 11.50 & 0.868 & 145 & 16 & 90 & Colourless & 1 & 492 \\
\hline 12 & 14.60 & 12 & 15.35 & 13.30 & 0.867 & 145 & 16 & 93 & Colourless & 1 & 417 \\
\hline 14 & - & - & - & - & - & - & - & - & Pale yellow & $\mathrm{s}$ & 373 \\
\hline
\end{tabular}

${ }^{\mathrm{a}}$ Synthesis performed in autoclave; ${ }^{\mathrm{b}}$ Synthesis performed in microwave reactor; ${ }^{\mathrm{c}} s-$ solid; $l$ - liquid; *density data provided by supplier.

Synthesis of $\left[\mathbf{P}_{4441}\right]$ Cl. A stoicheiometric amount of 60 tributylmethylphosphonium methylcarbonate $(75 \%$ solution in methanol, $0.103 \mathrm{~mol}$ ) and concentrated aqueous hydrochloric acid $(0.103 \mathrm{~mol})$ were weighed in separate beakers, $500 \mathrm{~cm}^{3}$ and $50 \mathrm{~cm}^{3}$, respectively. The acid was slowly added into the ionic liquid, while constantly stirring at room temperature, which 65 helped to reduce the amount of foam generated by the evolved $\mathrm{CO}_{2}$ gas. When $\mathrm{CO}_{2}$ evolution ceased, the reaction was considered as complete. The reaction mixture was transferred to a round-bottomed flask $\left(100 \mathrm{~cm}^{3}\right)$ and further dried at $65^{\circ} \mathrm{C}$ in vacuo for $48 \mathrm{~h}$. The reaction yield was $91.5 \%$ (23.8g); the product 70 was a colourless viscous liquid.

Synthesis of $\left[P_{4} 4_{4}\right.$ 2]Cl. The autoclave glass reactor was charged with a tributylphosphine solution in toluene (see Table 1) under a dinitrogen atmosphere, placed into the stainless steel cage holder, and quickly attached to the cover plate. A gas cylinder
75 containing chloroalkane (chloromethane or chloroethane) was connected to the autoclave through the gas inlet tube. The gas and inlet valves were opened after the set up was proved to be tight and the gas flow was maintained at approximately $2 \mathrm{~cm}^{3} \mathrm{~min}$ ${ }^{1}$.The reaction mixture was slowly heated over several hours in an 80 oil bath until the temperature inside of the reactor reached 145 ${ }^{\circ} \mathrm{C}$. The pressure in the reactor was built up by an excess of chloroalkane and did not exceed 4 bar with increasing temperature. The gas inlet was closed after approximately one hour and the reaction was maintained at $145{ }^{\circ} \mathrm{C}$ for two hours in 85 the case of chloromethane, and for an additional two hours in case of chloroethane. After the reaction was cooled down to room temperature, the pressure was released and the sample for ${ }^{31} \mathrm{P}$ NMR spectroscopy was taken to check for the disappearance of phosphine signal. The content of the reactor was then transferred 90 to a round-bottomed flask $\left(100 \mathrm{~cm}^{3}\right)$ and dried at $65{ }^{\circ} \mathrm{C}$ in vacuo for 48 hours. 
Synthesis of $\left[\mathbf{P}_{4} 4_{4}\right]$ Cl. A tributylphosphine solution in toluene ( 1 mol eq.) was mixed with 1 -chloropropane $(1.1 \mathrm{~mol}$ eq.) in a glass microwave vial $\left(20 \mathrm{~cm}^{3}\right)$ with an inserted stirring bar, under dinitrogen. The reaction mixture was transferred under a ${ }_{5} \mathrm{Suba}$ Seal ${ }^{\circledR}$ septum (purchased from Sigma Aldrich), avoiding any contact with air while transferring from the Atmosbag ${ }^{\circledR}$ to the shield vessel. The septum was removed and discarded immediately before the TMS screw cap was attached to the shield vessel. They were then placed inside the microwave cavity. The 10 reaction conditions were: $\operatorname{Ramp}(5 \mathrm{~min})$ to $180{ }^{\circ} \mathrm{C}$; hold at $180{ }^{\circ} \mathrm{C}$ (30 min), medium stirring, $500 \mathrm{~W}(50 \% \mathrm{max})$ power; pressure reached 3 bar. After the reaction was complete and cooled, the product was transferred to a round-bottomed flask $\left(25 \mathrm{~cm}^{3}\right)$ and dried at $65^{\circ} \mathrm{C}$ in vacuo for $48 \mathrm{~h}$.

${ }_{15}$ Synthesis of $\left[\mathbf{P}_{44_{n}}\right] \mathbf{C l}, \boldsymbol{n}=\mathbf{5 - 8}, 10$ or 12. Tributylphosphine (1 mol eq.) and 1-chloroalkane $(1.1 \mathrm{~mol}$ eq. $)$ were placed in a round-bottomed flask $\left(50 \mathrm{~cm}^{3}\right)$. The mixture was stirred and heated under a reflux condenser connected to a Schlenk line flushed with dinitrogen. The reaction mixture was heated in a 20 silicone oil bath up to $145{ }^{\circ} \mathrm{C}$ and maintained for 12 to $16 \mathrm{~h}$, depending on the alkyl chain length of chloroalkane used. In order to remove the excess of starting 1-chloroalkane $\left(\mathrm{C}_{n} \mathrm{H}_{2 n+1} \mathrm{Cl}\right)$, where $n \geq 5$, the purification step involved dissolution of product in water, followed by extraction with 25 ethyl ethanoate. All products were then dried at $65{ }^{\circ} \mathrm{C}$ in vacuo for $48 \mathrm{~h}$.

Table 2 Elemental analysis of $\left[\mathrm{P}_{444 n}\right] \mathrm{Cl}$ and identification of cations by $\mathrm{FAB}$, where peaks were assigned as $\left[\mathrm{M}^{+}\right]$.

\begin{tabular}{|c|c|c|c|c|c|c|c|c|c|c|}
\hline \multirow{2}{*}{$n$} & \multicolumn{2}{|c|}{$\mathrm{C} / \%$} & \multicolumn{2}{|c|}{$\mathrm{H} / \%$} & \multicolumn{2}{|c|}{$\mathrm{Cl} / \%$} & \multicolumn{2}{|c|}{$\mathrm{P} / \%$} & \multicolumn{2}{|c|}{$m / z$} \\
\hline & calc. & exp. & calc. & exp. & calc. & exp. & calc. & exp. & calc. & exp. \\
\hline 1 & 61.76 & 61.83 & 11.96 & 11.74 & 14.02 & 13.86 & 12.25 & 12.57 & 217.2 & 216.9 \\
\hline 2 & 63.02 & 63.35 & 12.09 & 12.12 & 13.29 & 13.61 & 10.50 & 10.92 & 231.2 & 230.9 \\
\hline 3 & 64.15 & 63.48 & 12.20 & 11.80 & 12.62 & 13.06 & 11.03 & 11.66 & 245.2 & 245.2 \\
\hline 4 & 65.16 & 64.55 & 12.31 & 12.64 & 12.02 & 12.21 & 10.50 & 10.60 & 259.3 & 259.2 \\
\hline 5 & 66.10 & 65.75 & 12.40 & 12.52 & 11.48 & 11.54 & 10.03 & 10.19 & 273.3 & 273.3 \\
\hline 6 & 66.95 & 66.65 & 12.48 & 12.64 & 10.98 & 10.96 & 9.59 & 9.75 & 287.3 & 287.2 \\
\hline 7 & 67.72 & 66.83 & 12.56 & 12.90 & 10.52 & 11.25 & 9.19 & 9.02 & 301.3 & 301.2 \\
\hline 8 & 68.44 & 68.23 & 12.64 & 12.13 & 10.10 & 10.32 & 8.82 & 9.32 & 315.3 & 315.3 \\
\hline 10 & 69.71 & 68.90 & 12.76 & 12.75 & 9.35 & 9.68 & 8.17 & 8.68 & 343.4 & 343.4 \\
\hline 12 & 70.81 & 70.89 & 12.87 & 12.23 & 8.71 & 8.77 & 7.61 & 8.11 & 371.4 & 371.6 \\
\hline 14 & 71.76 & 71.54 & 12.97 & 12.90 & 8.15 & 8.05 & 7.12 & 7.51 & 399.4 & 399.4 \\
\hline
\end{tabular}

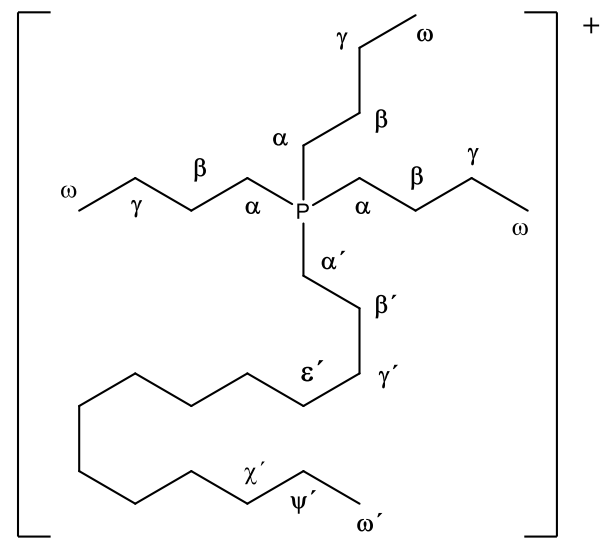

Fig. 2 The numbering convention used for structures of the cation described in Tables 3 and 4 . The fourth (variable) alkyl substitution on the phosphorus is labelled as a secondary chain $\left(\alpha^{\prime}, \beta^{\prime}, \gamma^{\prime}\right.$, etc. $)$ where terminal position takes priority, apart from positions $\alpha^{\prime}$ and $B^{\prime}$. 


\section{Journal Name}

Cite this: DOI: $10.1039 / \mathrm{c0xx} 00000 x$

www.rsc.org/xxxxxx

ARTICLE TYPE

Table 3 For $\left[\mathrm{P}_{444 n}\right] \mathrm{Cl},{ }^{1} \mathrm{H}$ NMR shifts $\left(\delta / \mathrm{ppm}, d_{6}\right.$-propanone, $\left.300 \mathrm{MHz}, 21{ }^{\circ} \mathrm{C}\right)$, with coupling constant $\left({ }^{2} J_{\mathrm{PH}} / \mathrm{Hz}\right)$ and ${ }^{31} \mathrm{P}\left\{{ }^{1} \mathrm{H}\right\} \mathrm{NMR}$ shifts $\left(\delta / \mathrm{ppm}, d_{6}\right.$-propanone, $\left.120 \mathrm{MHz}, 2{ }^{\circ} \mathrm{C}\right)$, peaks were assigned according to Figure 2.

\begin{tabular}{|c|c|c|c|c|c|c|c|c|c|}
\hline \multirow[b]{2}{*}{$n$} & \multicolumn{2}{|c|}{$\mathbf{H}^{\alpha, a^{\prime}}$} & \multicolumn{2}{|l|}{$\mathbf{H}^{\mathrm{B}, \mathrm{B}^{\prime}}$} & \multicolumn{2}{|c|}{$\mathbf{H}^{\gamma, \gamma^{-}-\psi^{\prime}}$} & \multicolumn{2}{|l|}{$\mathbf{H}^{\omega, \omega^{\prime}}$} & \multirow{2}{*}{$\begin{array}{c}{ }^{31} \mathbf{P} \\
\delta / p p m\end{array}$} \\
\hline & $\delta /$ ppm & intensity & $\delta /$ ppm & intensity & $\delta / \mathbf{p p m}$ & intensi $\mathrm{y}$ & $\delta /$ ppm & intensity & \\
\hline $\mathbf{1}$ & $2.50-2.60(\mathrm{~m}), 2.08\left(\mathrm{~d},{ }^{2} J=14.4\right)$ & $6 \mathrm{H}, 3 \mathrm{H}^{\left(\alpha^{\prime}\right)}$ & $1.47-1.60(\mathrm{~m})$ & $6 \mathrm{H}$ & $1.31-1.43(\mathrm{~m})$ & $6 \mathrm{H}$ & $0.81-0.86(\mathrm{~m})$ & $9 \mathrm{H}$ & 33.76 \\
\hline 2 & $2.49-2.63(\mathrm{~m})$ & $8 \mathrm{H}$ & $1.48-1.60(\mathrm{~m}), 1.11-1.22(\mathrm{~m})$ & $6 \mathrm{H}, 3 \mathrm{H}^{(\beta)}$ & $1.31-1.43(\mathrm{~m})$ & $6 \mathrm{H}$ & $0.81-0.86(\mathrm{~m})$ & $9 \mathrm{H}$ & 36.35 \\
\hline 3 & $2.44-2.57(\mathrm{~m}$ & $8 \mathrm{H}$ & $1.48-1.65(\mathrm{~m})$ & $8 \mathrm{H}$ & $0.94-0.99(\mathrm{~m}), 1.31-1.43(\mathrm{~m})$ & $3 \mathrm{H}^{\left(\gamma^{\prime}\right)}, 6 \mathrm{H}$ & $0.81-0.86(\mathrm{~m})$ & $9 \mathrm{H}$ & 34.19 \\
\hline 4 & $2.45-2.55(\mathrm{~m})$ & $8 \mathrm{H}$ & $1.48-1.61(\mathrm{~m})$ & $8 \mathrm{H}$ & $1.31-1.43(\mathrm{~m})$ & $8 \mathrm{H}$ & $0.81-0.85(\mathrm{~m})$ & $12 \mathrm{H}$ & 34.61 \\
\hline 5 & $2.47-2.58(\mathrm{~m})$ & $8 \mathrm{H}$ & $1.48-1.61(\mathrm{~m})$ & $8 \mathrm{H}$ & $1.20-1.43(\mathrm{~m})$ & $10 \mathrm{H}$ & $0.75-0.86(\mathrm{~m})$ & $12 \mathrm{H}$ & 34.57 \\
\hline 6 & $2.50-2.60(\mathrm{~m})$ & $8 \mathrm{H}$ & $1.48-1.61(\mathrm{~m})$ & $8 \mathrm{H}$ & $1.20-1.25(\mathrm{~m}), 1.32-1.44(\mathrm{~m})$ & $4 \mathrm{H}, 8 \mathrm{H}$ & $0.74-0.79(\mathrm{~m}), 0.81-0.86(\mathrm{~m})$ & $3 \mathrm{H}, 9 \mathrm{H}$ & 34.53 \\
\hline 7 & $2.50-2.60(\mathrm{~m})$ & $8 \mathrm{H}$ & $1.48-1.61(\mathrm{~m})$ & $8 \mathrm{H}$ & $1.15-1.27(\mathrm{~m}), 1.32-1.44(\mathrm{~m})$ & $6 \mathrm{H}, 8 \mathrm{H}$ & $0.74-0.78(\mathrm{~m}), 0.81-0.86(\mathrm{~m})$ & $3 \mathrm{H}, 9 \mathrm{H}$ & 34.51 \\
\hline 8 & $2.39-2.50(\mathrm{~m})$ & $8 \mathrm{H}$ & $1.38-1.51(\mathrm{~m})$ & $8 \mathrm{H}$ & $1.07-1.15(\mathrm{~m}), 1.21-1.34(\mathrm{~m})$ & $8 \mathrm{H}, 8 \mathrm{H}$ & $0.63-0.67(\mathrm{~m}), 0.71-0.76(\mathrm{~m})$ & $3 \mathrm{H}, 9 \mathrm{H}$ & 34.51 \\
\hline 10 & $2.49-2.60(\mathrm{~m})$ & $8 \mathrm{H}$ & $1.48-1.61(\mathrm{~m})$ & $8 \mathrm{H}$ & $1.16-1.27(\mathrm{~m}), 1.32-1.44(\mathrm{~m})$ & $12 \mathrm{H}, 8 \mathrm{H}$ & $0.73-0.77(\mathrm{~m}), 0.81-0.86(\mathrm{~m})$ & $3 \mathrm{H}, 9 \mathrm{H}$ & 34.48 \\
\hline 12 & $2.49-2.60(\mathrm{~m})$ & $8 \mathrm{H}$ & $1.48-1.63(\mathrm{~m})$ & $8 \mathrm{H}$ & $1.16-1.26(\mathrm{~m}), 1.48-1.63(\mathrm{~m})$ & $16 \mathrm{H}, 8 \mathrm{H}$ & $0.73-0.77(\mathrm{~m}), 0.81-0.86(\mathrm{~m})$ & $3 \mathrm{H}, 9 \mathrm{H}$ & 34.46 \\
\hline 14 & $2.46-2.56(\mathrm{~m})$ & $8 \mathrm{H}$ & $1.48-1.61(\mathrm{~m})$ & $8 \mathrm{H}$ & $1.16-1.27(\mathrm{~m}), 1.32-1.44(\mathrm{~m})$ & $20 \mathrm{H}, 8 \mathrm{H}$ & $0.73-0.77(\mathrm{~m}), 0.81-0.86(\mathrm{~m})$ & $3 \mathrm{H}, 9 \mathrm{H}$ & 34.52 \\
\hline
\end{tabular}

5 Table 4 For $\left[\mathrm{P}_{444 n}\right] \mathrm{Cl},{ }^{13} \mathrm{C}\left\{{ }^{1} \mathrm{H}\right\}$ NMR shifts $\left(\delta / \mathrm{ppm}, d_{6}\right.$-propanone, $\left.75 \mathrm{MHz}, 21{ }^{\circ} \mathrm{C}\right)$, with coupling constants $\left({ }^{1} J_{\mathrm{PC}} / \mathrm{Hz}\right)$, peaks were assigned according to Figure 2

\begin{tabular}{|c|c|c|c|c|c|}
\hline & $\mathbf{C}^{\alpha, \alpha^{\prime}}$ & $\mathbf{C}^{\beta, \beta^{\prime}}$ & $\mathbf{C}^{\gamma, \gamma^{\prime}}$ & $\mathbf{C}^{\varepsilon^{\prime}-\psi^{\prime}}$ & $\mathbf{C}^{\omega, \omega^{\prime}}$ \\
\hline$n$ & ס/ppm & ס/ppm & ס/ppm & ס/ppm & 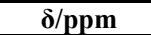 \\
\hline 1 & $4.99\left(\mathrm{~d}, J_{\mathrm{PC}}=51.75 \mathrm{~Hz}\right), 20.99\left(\mathrm{~d}, J_{\mathrm{PC}}=49.13 \mathrm{~Hz}\right)$ & 24.63 & $24.97,25.19$ & & 14.30 \\
\hline 2 & $13.60\left(\mathrm{~d}, J_{\mathrm{PC}}=48.90 \mathrm{~Hz}\right), 19.34\left(\mathrm{~d}, J_{\mathrm{PC}}=47.55 \mathrm{~Hz}\right)$ & $24.71,6.70$ & $25.03,25.24$ & & 14.23 \\
\hline 3 & $19.71\left(\mathrm{~d}, J_{\mathrm{PC}}=47.55 \mathrm{~Hz}\right), 21.90\left(\mathrm{~d}, J_{\mathrm{PC}}=47.33 \mathrm{~Hz}\right)$ & $24.73,16.66$ & $25.03,25.23$ & & $14.23,16.35$ \\
\hline $4^{*}$ & $19.70\left(\mathrm{~d}, J_{\mathrm{PC}}=47.55 \mathrm{~Hz}\right)$ & 24.74 & $25.03,25.23$ & & 14.23 \\
\hline 5 & $19.67\left(\mathrm{~d}, J_{\mathrm{PC}}=47.55 \mathrm{~Hz}\right), 19.81\left(\mathrm{~d}, J_{\mathrm{PC}}=47.40 \mathrm{~Hz}\right)$ & $23.10,24.78$ & $25.04,25.25,34.08,34.28$ & 22.43 & $14.26,14.61$ \\
\hline 6 & $19.72\left(\mathrm{~d}, J_{\mathrm{PC}}=47.46 \mathrm{~Hz}\right), 19.91\left(\mathrm{~d}, J_{\mathrm{PC}}=47.33 \mathrm{~Hz}\right)$ & $23.10,24.79$ & $25.04,25.25$ & $22.43,34.08,34.29$ & $14.27,14.62$ \\
\hline 7 & $19.74\left(\mathrm{~d}, J_{\mathrm{PC}}=47.48 \mathrm{~Hz}\right), 19.99\left(\mathrm{~d}, J_{\mathrm{PC}}=47.25 \mathrm{~Hz}\right)$ & $23.57,24.82$ & $25.06,25.27$ & $22.80,31.67,31.87,31.29$ & $14.31,14.81$ \\
\hline 8 & $19.74\left(\mathrm{~d}, J_{\mathrm{PC}}=47.46 \mathrm{~Hz}\right), 19.97\left(\mathrm{~d}, J_{\mathrm{PC}}=47.25 \mathrm{~Hz}\right)$ & $23.76,24.81$ & $25.06,25.27$ & $22.76,30.29,31.99,32.20,32.99$ & $14.29,14.84$ \\
\hline 10 & $19.75\left(\mathrm{~d}, J_{\mathrm{PC}}=47.48 \mathrm{~Hz}\right), 19.98\left(\mathrm{~d}, J_{\mathrm{PC}}=47.25 \mathrm{~Hz}\right)$ & $23.77,24.83$ & $25.06,25.72$ & $22.81,30.10,30.30,32.00,32.21,33.00$ & $14.32,14.86$ \\
\hline 12 & $19.77\left(\mathrm{~d}, J_{\mathrm{PC}}=47.40 \mathrm{~Hz}\right), 20.00\left(\mathrm{~d}, J_{\mathrm{PC}}=47.10 \mathrm{~Hz}\right)$ & $23.78,24.85$ & $25.08,25.29$ & $22.85,30.23,30.50,30.75,32.03,32.23,33.00$ & $14.36,14.89$ \\
\hline 14 & $19.73\left(\mathrm{~d}, J_{\mathrm{PC}}=47.55 \mathrm{~Hz}\right), 19.95\left(\mathrm{~d}, J_{\mathrm{PC}}=47.25 \mathrm{~Hz}\right)$ & $23.76,24.79$ & $25.05,25.26$ & $22.78,30.11,30.36,30.62,30.80,31.99,32.19,33.08$ & $14.27,14.83$ \\
\hline
\end{tabular}

*Due to the symmetry of the compound, all the peak assignments are equal. 


\section{Cite this: DOI: $10.1039 / \mathrm{c0xx} 00000 \mathrm{x}$}

\section{Results and discussion}

\section{Synthetic procedures}

The salts, $\left[\mathrm{P}_{444 \mathrm{n}}\right] \mathrm{Cl}$, where $n=2,3,5,6,7,8,10$ and 12 , were prepared by nucleophilic $\left(\mathrm{S}_{\mathrm{N}} 2\right)$ addition of tributylphosphine to 5 the appropriate linear chloroalkane. As the tributylphosphine was supplied in $50 \%(\mathrm{v} / \mathrm{v})$ toluene solution (in order to reduce flammability), the solvent had to be removed when the reaction was complete. The toluene retarded the reaction rate, such that it became close to that of the neat reactions of trioctylphosphine. ${ }^{11}$

10 A different, and more convenient, approach was adopted for the synthesis of $\left[\mathrm{P}_{4441}\right] \mathrm{Cl}$ due to the availability of $\left[\mathrm{P}_{4} 4_{4}{ }_{1}\right]\left[\mathrm{CH}_{3} \mathrm{OCO}_{2}\right]$ ( ex Cytec, Canada), which was prepared by the reaction between tributylphosphine and dimethylcarbonate. This can also be prepared easily in the laboratory by a procedure 15 analogous to one described elsewhere. ${ }^{33}$ Once formed, this is a versatile reagent, reacting with any Brønsted acid, HY, to quantitatively yield $\left[\mathrm{P}_{4} 4_{4}\right]$ Y (see Figure 3 ). In the specific case of $\left[\mathrm{P}_{444}\right] \mathrm{Cl}$, the reagent was treated with concentrated aqueous hydrochloric acid.

$$
\begin{aligned}
& \mathrm{P}_{444}+\left(\mathrm{CH}_{3} \mathrm{O}\right)_{2} \mathrm{CO} \\
& \qquad-\mathrm{CO}_{2} \\
& {\left[\mathrm{P}_{4441}\right]\left[\mathrm{CH}_{3} \mathrm{OCO}_{2}\right]} \\
& +\mathrm{HY} \downarrow-\mathrm{CO}_{2} / \mathrm{CH}_{3} \mathrm{OH}
\end{aligned}
$$

Fig. 3 A generic synthesis of tributylmethylphosphonium salts

The average yield for all the compounds reported in Table 2 was $94 \%$, with the final purification being the yield reducing step, which was performed to remove the excess of chloroalkane from 25 the product, and consisted in the dissolution of the hydrophilic ionic liquid in water followed by washing with ethyl ethanoate. Water and ethyl ethanoate were then removed on a rotary evaporator and the products were further dried at $65^{\circ} \mathrm{C}$, in vacuo, for $48 \mathrm{~h}$. All liquid products were colourless, while solids were

30 typically white to pale yellow waxes. All the salts $\left[\mathrm{P}_{444 n}\right] \mathrm{Cl}$ were hydrophilic and dissolved in water.

\section{Nuclear magnetic resonance spectroscopy}

${ }^{31} \mathbf{P}$ NMR spectra. The ${ }^{31} \mathrm{P}\left\{{ }^{1} \mathrm{H}\right\} \quad$ NMR spectra of the alkyltributylphosphonium chlorides (see Table 3) each exhibited 35 a singlet at $+34.49 \pm 0.30 \mathrm{ppm}$, with the two exceptions of $\left[\mathrm{P}_{44_{4}}\right] \mathrm{Cl}$ and $\left[\mathrm{P}_{44_{4}}\right] \mathrm{Cl}$, where the signals were at $+33.76 \mathrm{ppm}$ and $+36.35 \mathrm{ppm}$, respectively. A similar phenomenon was observed for $\left[\mathrm{P}_{8} 8_{8}\right] \mathrm{Cl}$, where the methyl and ethyl salts also exhibited different chemical shifts from the rest of the series. The ${ }_{40}$ singlet was accompanied by minor satellites as a result of ${ }^{13} \mathrm{C}-{ }^{31} \mathrm{P}$ coupling $\left({ }^{1} J_{\mathrm{CP}}=47.22 \pm 0.46 \mathrm{~Hz}\right)$ to the $\alpha$-carbon.
As the tertiary tributylphosphine signal is at $-31.06 \mathrm{ppm}$ (most of tertiary alkylphosphines exhibit signals in the $\delta-30$ to $-60 \mathrm{ppm}$ range), monitoring of the reactions was very straightforward. The ${ }_{45}$ purity of the starting phosphine was determined by ${ }^{31} \mathrm{P}$ NMR spectroscopy as ca. 95\%. The tributylphosphine is industrially prepared (Cytec) by free radical anti-Markovnikov addition of phosphine to 1-butene, ${ }^{34}$ but there is a small fraction which proceeds in classic Markovnikov mode, ${ }^{35}$ where phosphorus adds 50 to the $\beta$-carbon, forming dibutyl(sec-butyl)phosphine (-17.88 ppm, Figure 4).

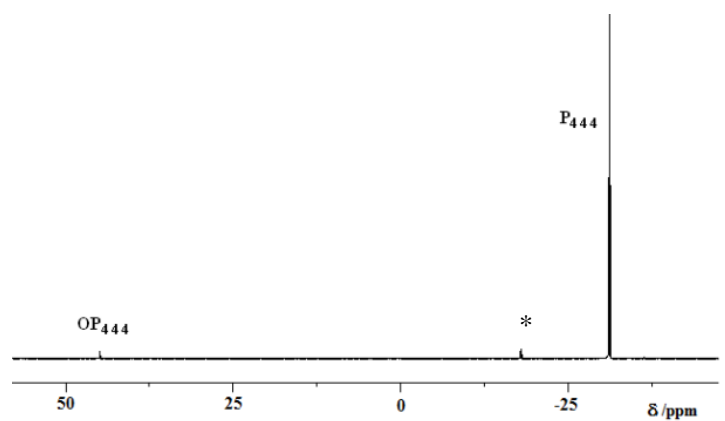

Fig. 4 The ${ }^{31} \mathrm{P}\left\{{ }^{1} \mathrm{H}\right\} \mathrm{NMR}$ spectrum $\left(d_{6}\right.$-propanone, $\left.120 \mathrm{MHz}, 21{ }^{\circ} \mathrm{C}\right)$ with peak assignments for tributylphosphine, tributylphosphine oxide and 55 dibutyl(sec-butyl)phosphine (marked with asterisk).

In addition, at $+44.90 \mathrm{ppm}$, traces of tributylphosphine oxide were observed. Its presence indicates the extreme sensitivity of tributylphosphine to aerial oxidation and reinforces the need for exceptional care in handling the phosphine.

${ }_{60}{ }^{1} \mathbf{H}$ and ${ }^{13} \mathbf{C}$ NMR spectra. Proton and carbon-13 NMR spectra of $\left[\mathrm{P}_{44_{n}}\right] \mathrm{Cl}$ are reported and assigned in Tables 3 and 4. A major difference in the chemical shifts of the alkyl protons can be observed with an increasing number of carbon atoms in the fourth alkyl chain on the cation. The protons of the methyl substituent in ${ }_{65}\left[\mathrm{P}_{44_{4}}\right] \mathrm{Cl}$, see Figure 5(B), can be observed as a doublet due to the strong phosphorus-hydrogen coupling.

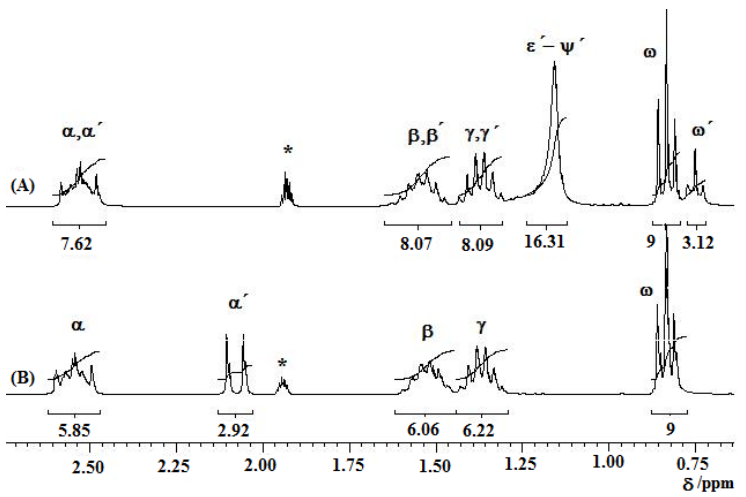

Fig. 5 The ${ }^{1} \mathrm{H}$ NMR spectra $\left(d_{6}\right.$ propanone, $\left.300 \mathrm{MHz}, 21^{\circ} \mathrm{C}\right)$ of (A) $\left[\mathrm{P}_{44412}\right] \mathrm{Cl}$ and (B) $\left[\mathrm{P}_{4441}\right] \mathrm{Cl}$; peaks are labelled according to Figure 2 70 (individual peaks are assigned in Table 3), solvent is assigned as (*).

As the number of methylene groups increases, the shift of the 
methyl group at the end of the fourth alkyl substitution moves towards to lower magnetic field until it reaches the multiplet belonging to the methyl groups of the three remaining butyl substitutions on the cation. The multiplet belonging to protons 5 bonded to a terminal carbon visibly split when $n=6$, shifting the signal of $-\mathrm{CH}_{3}$ group on the fourth alkyl substituent further downfield, Figure 5 (see Table 3). The sensitivity of the unique terminal methyl group is obvious in the ${ }^{13} \mathrm{C}$ NMR spectra as well, see Table 4 and Figure 6. With increasing $n$, the signal of the 10 terminal group approaches that of the remaining methyl groups at $n=4$, when the compound adopts tetrahedral symmetry. As $n$ becomes $>4$, the signal at +14.23 ppm splits into two signals and remains effectively unchanged up to $n=14$.

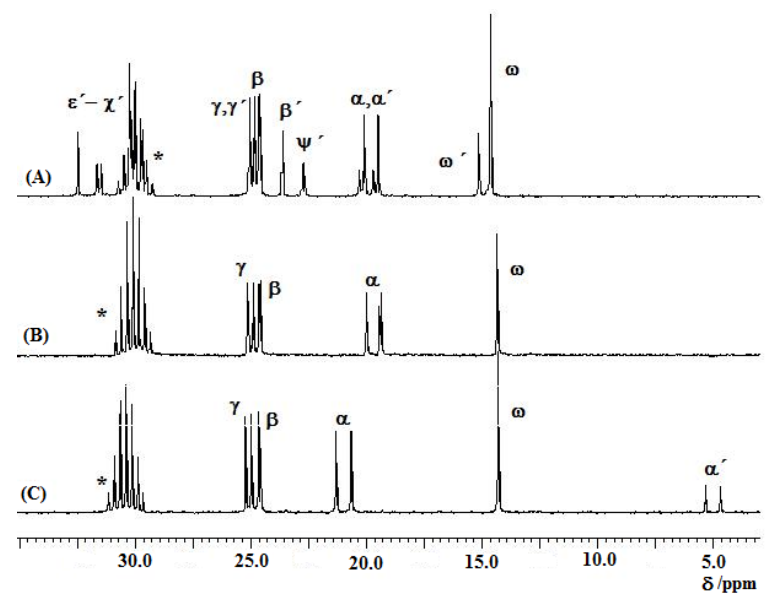

${ }_{15}$ Fig. 6 The ${ }^{13} \mathrm{C}\left\{{ }^{1} \mathrm{H}\right\}$ NMR spectra $\left(d_{6}\right.$ propanone, $\left.120 \mathrm{MHz}, 21^{\circ} \mathrm{C}\right)$ of $(\mathrm{A})$ $\left[\mathrm{P}_{4448}\right] \mathrm{Cl}$, (B) $\left[\mathrm{P}_{4444}\right] \mathrm{Cl}$ and $(\mathrm{C})\left[\mathrm{P}_{4441}\right] \mathrm{Cl}$; peaks are labelled according to Figure 2 (individual peaks are assigned in Table 4), solvent is assigned as $(*)$.

20 In order to justify the assignments for the NMR spectra, show in Tables 3 and 4; and Figure 2, 2-D COSY and 2-D HSQC spectra, respectively, see Figures $\mathbf{7}$ and $\mathbf{8}$, are presented for $\left[\mathrm{P}_{4} 44_{3}\right] \mathrm{Cl}$.

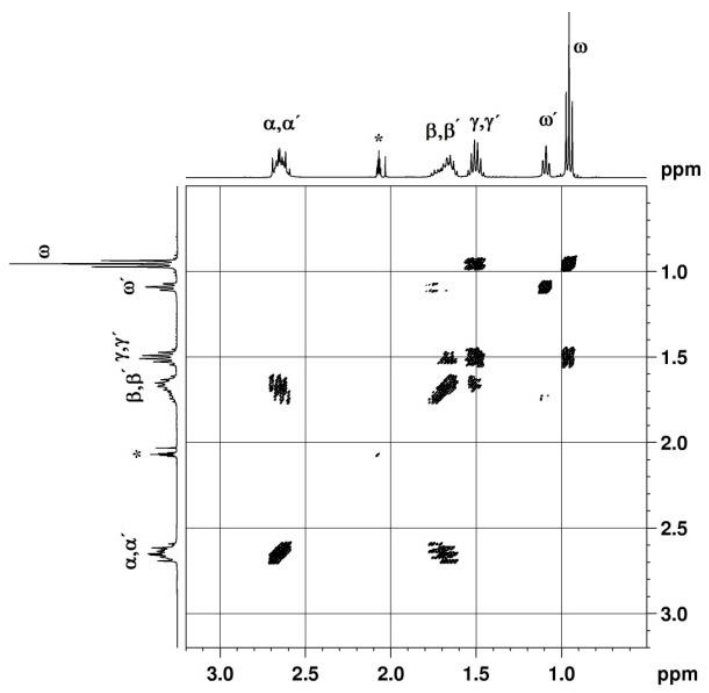

${ }_{25}$ Fig. 7 The 2-D ${ }^{1} \mathrm{H},{ }^{1} \mathrm{H}-\mathrm{COSY}$ NMR spectrum of $\left[\mathrm{P}_{4443}\right] \mathrm{Cl}\left(d_{6}\right.$-propanone, $\left.400 \mathrm{MHz}, 21^{\circ} \mathrm{C}\right)$, solvent is assigned as $\left({ }^{*}\right)$ and peaks according to

Figure 2.

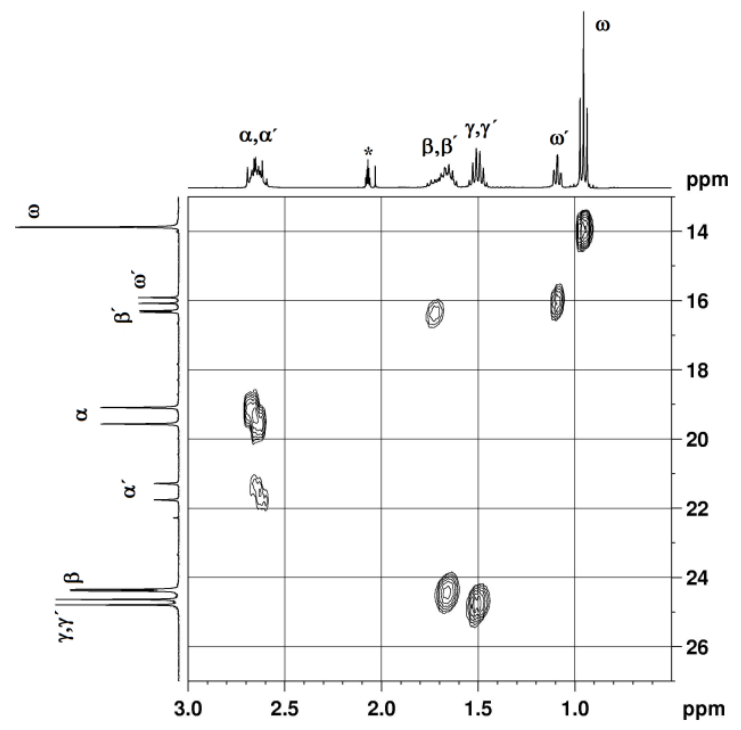

Fig. 8 The 2-D ${ }^{1} \mathrm{H},{ }^{13} \mathrm{C}\left\{{ }^{1} \mathrm{H}\right\}$-HSQC NMR spectrum of $\left[\mathrm{P}_{4443}\right] \mathrm{Cl}$ 30 ( $d_{6}$-propanone, $400 \mathrm{MHz}, 21^{\circ} \mathrm{C}$ ), solvent is assigned as $(*)$ and peaks
labelled according to Figure 2.

These experiments serve as a justification for assignment of chemical shifts, especially in ${ }^{13} \mathrm{C}$ NMR. The chemical shifts, when assigned according to ${ }^{13} \mathrm{C}$ NMR predictor (ChemBioDraw ${ }_{35}$ Ultra $\left.^{\circledR}\right),{ }^{36}$ were in excellent agreement with results obtained from 2-D HSQC NMR experiment.

\section{Single crystal analysis}

The crystal structure of $\left[\mathrm{P}_{44_{4}}\right] \mathrm{Cl}$ has been determined by $\mathrm{X}$-ray 40 diffraction, which confirmed the absence of any solvation. This salt crystallised from its melt in a monoclinic lattice, space group $P 2_{1} / c$, with one ion pair in the asymmetric unit (see experimental section). The cation has been refined with a positional disorder of two components (50/50 site occupancy factor ratio), as seen in ${ }_{45}$ Figure 9. For both cation components, the central phosphorus atoms have been modelled as occupying identical positions.

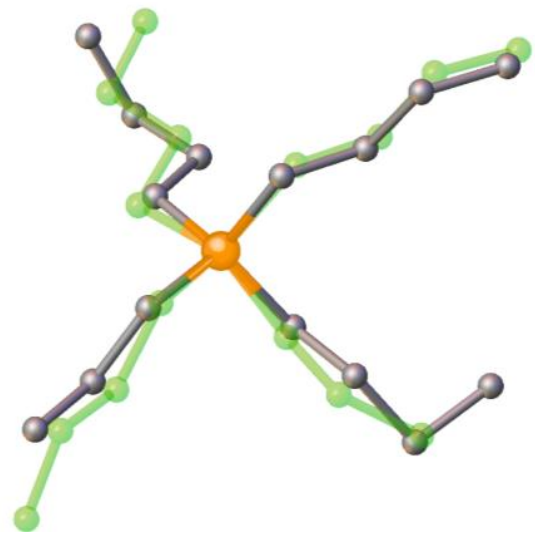

Fig. 9 A superimposed view of both disordered cation fragments, $\mathbf{A A}$ and $\mathbf{A G}$, in the crystal structure of $\left[\mathrm{P}_{4443}\right] \mathrm{Cl}$. Orange = phosphorus; the 50 carbon atoms are coloured grey (AG) and green (AA) to distinguish the cations; all hydrogen atoms have been omitted for clarity.

When comparing both cation conformations, the propyl chain and one of the butyl chains are located in exchanged regions and these two conformations are randomly distributed throughout the 
lattice. The conformations adopted within the constraints are consistent with known quaternary phosphonium salts, and the average $\mathrm{P}-\mathrm{C}$ bond distance in both cation fragments of $\left[\mathrm{P}_{44_{4} 3}\right] \mathrm{Cl}$ structure is $1.80 \pm 0.03 \AA$, in good agreement with those s previously reported, $1.79 \pm 0.02 \AA{ }^{37}$ In one conformation, the alkyl chains display all-anti conformations, AA, whereas the other conformation has two butyl chains with their terminal methyl groups in a gauche conformation, i.e. the bonds between the third and fourth carbon atoms show marked torsions (dihedral 10 angles $=64$ and $83^{\circ}$, see Figure 9), AG.

By detailed examination of the crystal structure of $\left[\mathrm{P}_{4443}\right] \mathrm{Cl}$, it has been observed that each cation is surrounded by three chloride anions; see Figure 10(A). Conversely, each anion is surrounded by three cations; Figure 10(B). A number of short 15 contacts have been found between the chloride anion and hydrogen atoms in the $\alpha$ position to the phosphorus atom (Figure 10). The distances of such contacts in conformer AA are $2.62,2.70,2.78,2.79$ and $2.85 \AA$, giving an average of 2.75(9), and in conformer AG are 2.48, 2.73, 2.83, 2.84 and $2.91 \AA$ giving 20 an average of 2.76(17) $\AA$ : these contacts are significantly shorter than the sum of Van der Waals radii $(2.95 \AA) .{ }^{38,39}$ This suggests that, in addition to the strong electrostatic attraction between the chloride anions and the positively charged phosphonium cations, hydrogen bonding should also be of significance in the solid state 25 of $\left[\mathrm{P}_{44} 4_{3}\right] \mathrm{Cl}$. Furthermore, as expected, the $\mathrm{P} \cdots \mathrm{Cl}$ distances were found in the 3.93-4.34 $\AA$ range, well above the sum of Van der Waals radii $(3.55 \AA){ }^{38,39}$

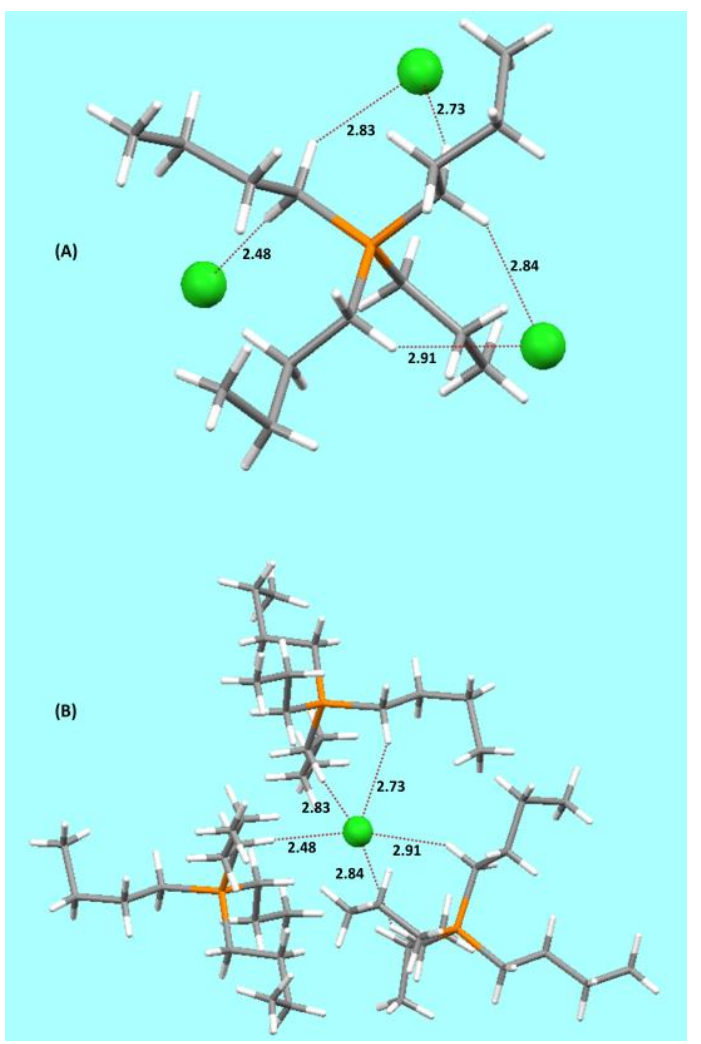

Fig. 10 (A) The anion coordination around the phosphonium cation and

(B) the cation coordination around the chloride anion in the crystal structure of $\left[\mathrm{P}_{4443}\right] \mathrm{Cl}$. For clarity, only one of the cation components (AG) is shown. Orange = phosphorus, grey $=$ carbon, white $=$ hydrogen, and green $=$ chlorine. $\mathrm{Cl} \cdots \mathrm{H}$ contacts $(\AA)$ are represented by dashed red lines.
35 As seen in Figure 11, the chloride anions and the phosphorus atom of the cations in $\left[\mathrm{P}_{44} 4_{3}\right] \mathrm{Cl}$ form layers parallel to the crystallographic $b c$ plane throughout the structure. The methyl ends of the alkyl chains occupy the boundaries of the segregated interlayers. Such a mode of packing resembles those found in the 40 lattices of $\left[\mathrm{N}_{4444}\right] \mathrm{Br}^{40}$ and $\left[\mathrm{N}_{4444}\right] \mathrm{I}^{41}$ both these salts crystallising in monoclinic lattices, as is the case for $\left[\mathrm{P}_{4443}\right] \mathrm{Cl}$. This is not surprising, given the structural similarity of these salts with the one reported here.

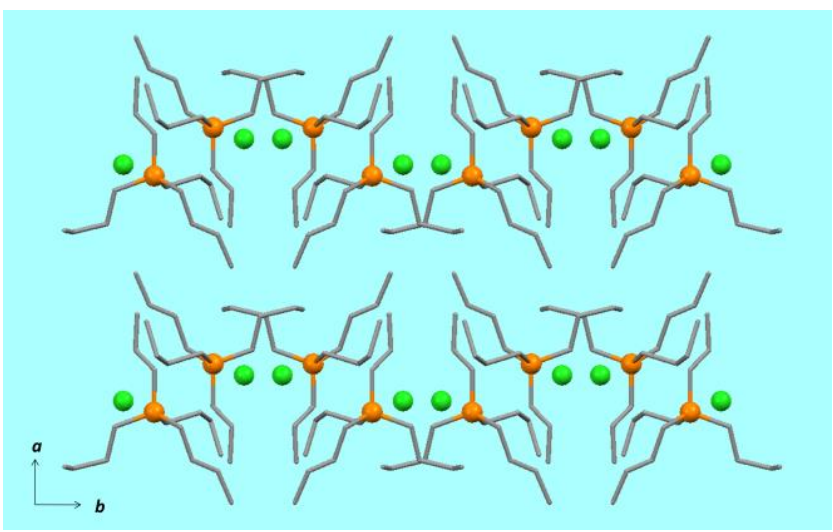

${ }_{45}$ Fig. 11 A view of the crystal packing in the crystal structure of $\left[\mathrm{P}_{4443}\right] \mathrm{Cl}$, showing the arrangement into layers parallel to the crystallographic $b c$ plane. The colours are as in Figure 10. For clarity, only one of the cation components (AG) is shown and hydrogen atoms have been omitted.

The crystal structure of $\left[\mathrm{P}_{44_{4}}\right] \mathrm{Cl}$ reported here is, to the best 50 of our knowledge, the first example of a structure of an anhydrous chloride salt of a phosphonium cation bearing only alkyl substituents. It should be noted that the crystal structures of tris(cyclohexyl)methylphosphonium chloride trihydrate ${ }^{42}$ and tetramethylphosphonium chloride monohydrate ${ }^{43}$ have been 55 reported, where the structures are dominated by strong hydrogen bonds between water and the chloride ions. Anhydrous analogues for other halides have been structurally determined, namely

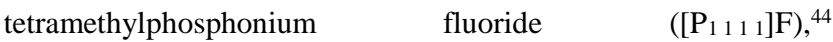
tetrakis(decyl)phosphonium bromide $\left(\left[\begin{array}{llll}\mathrm{P}_{1} & 10 & 10 & 10\end{array}\right] \mathrm{Br}\right),{ }^{45}$ and a ${ }_{60}$ small number of alicyclic phosphonium iodides. ${ }^{46-48}$ Furthermore, different polymorphs of anhydrous tetraethylammonium ${ }^{49,50}$ and 1-methyl-1-propylpyrrolidinium ${ }^{51,52}$ chlorides are also known.

A comparison between interionic $\mathrm{H} \cdots \mathrm{X}$ and $\mathrm{E} \cdots \mathrm{X}(\mathrm{E}=\mathrm{N}$ or $\mathrm{P}$, $\mathrm{X}=$ halide) distances for the salt reported here and for previously 65 reported phosphonium and ammonium salts is shown in Table 5. Although the number of structures is rather limited, especially for tetraalkylphosphonium halides, some patterns become evident:

(1) Strengthening of the hydrogen bonds is observed in the sequence $\mathrm{F}^{-}>\mathrm{Cl}^{-}>\mathrm{Br}^{-}>\mathrm{I}^{-}$, as expected.

70 (2) Increasing anion volumes in the order $\mathrm{F}^{-}<\mathrm{Cl}^{-}<\mathrm{Br}^{-}<\mathrm{I}^{-}$cause, not surprisingly, an increase in the interionic distances.

(3) Steric encumbrance around the central phosphorus or nitrogen atoms in the cations greatly affects the cation-anion separation distances; those cations containing methyl and/or cyclised 75 substituents are demonstrably less hindered, allowing a much closer approach of the halide anions to the central phosphorus or nitrogen atoms.

(4) The larger size of the phosphorus atom, as compared to nitrogen, may lead to a more open environment around itself, and 80 to a closer approach of the halide. 
Table 5 Average interionic distances ${ }^{a}$ in the crystal structure of $\left[\mathrm{P}_{4443}\right] \mathrm{Cl}$ and in related fully alkylated phosphonium or ammonium halides ${ }^{c}$.

\begin{tabular}{|c|c|c|c|}
\hline & $\begin{array}{l}\text { average } \\
d\left(\mathrm{C}_{a} \mathrm{H} \cdots\right. \\
\mathrm{X})^{a}\end{array}$ & $\begin{array}{l}\text { average } \\
d\left(\mathrm{C}_{\beta} \mathrm{H} \cdots\right. \\
\mathrm{X})^{a}\end{array}$ & $\begin{array}{l}\text { minimum } \\
d(\mathrm{E} \cdots \mathrm{X})^{b}\end{array}$ \\
\hline \multicolumn{4}{|l|}{ Phosphonium salts $(E=P)$} \\
\hline$\left[\mathrm{P}_{1} 1 \frac{1}{1}\right] \mathrm{F}^{d}$ & $2.27(9)$ & - & $3.385(1)$ \\
\hline$\left[\mathrm{P}_{4443}\right] \mathrm{Cl}^{e}$ & $2.75(13)$ & - & $3.955(2)$ \\
\hline 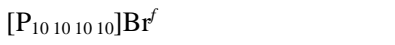 & - & $2.95(2)$ & $4.858(2)$ \\
\hline $\begin{array}{l}{\left[\mathrm{P}_{c y c l o-4} \text { cyclo-4] }\right]^{g}} \\
\left.\left[\mathrm{P}_{c y c l o-422}\right]\right]^{h}\end{array}$ & $\begin{array}{l}3.175 \\
2.97\end{array}$ & $\begin{array}{l}3.175 \\
-\end{array}$ & $\begin{array}{l}4.531(2) \\
4.628(2)\end{array}$ \\
\hline \multicolumn{4}{|l|}{ Ammonium salts $(\mathrm{E}=\mathrm{N})$} \\
\hline$\left[\mathrm{C}_{3} \mathrm{mpyrr}\right] \mathrm{Cl}$ (cyclic) $)^{i, j}$ & $2.78(5)$ & $2.78(2)$ & $\begin{array}{l}3.892(1) \\
3.89-3.91\end{array}$ \\
\hline$\left[\mathrm{N}_{2222}\right] \mathrm{Cl}^{k}$ & $2.81(10)$ & $2.89(5)$ & $\begin{array}{l}4.278(1) \\
4.27-4.37\end{array}$ \\
\hline$\left[\mathrm{N}_{\text {cyclo-4 cyclo-4 }}\right] \mathrm{Br}$ (spiro) ${ }^{l}$ & 2.853 & $2.98(6)$ & $4.120(6)$ \\
\hline$\left[\mathrm{C}_{n} \mathrm{mpyrr}\right] \mathrm{Br}(\mathrm{cyclic})^{j, m}$ & 2.94(8) & $2.98(3)$ & $\begin{array}{l}4.235(4) \\
4.23-4.26\end{array}$ \\
\hline$\left[\begin{array}{lllllllllllll}\mathrm{N}_{1} & 1 & 1\end{array}\right] \mathrm{Br}^{n}$ & 2.976 & - & $4.373(1)$ \\
\hline$\left[\mathrm{N}_{11 n m}\right] \mathrm{Br}^{o}$ & $2.90(9)$ & 2.986 & $\begin{array}{l}4.065(5) \\
4.06-4.20\end{array}$ \\
\hline$\left[\mathrm{NR}_{4}\right] \mathrm{Br}(\mathrm{R}>\mathrm{Me})^{p, q}$ & $2.90(9)$ & 2.97(7) & $\begin{array}{l}4.369(8) \\
4.36-4.94\end{array}$ \\
\hline$\left[\mathrm{C}_{n} \mathrm{mpyrr}\right] \mathrm{I}$ or $\left[\mathrm{C}_{1}\right.$ mpip]I $(\text { cyclic })^{j, r}$ & $3.13(5)$ & - & $\begin{array}{l}4.296(1) \\
4.29-4.74\end{array}$ \\
\hline$\left[\begin{array}{lllllll}\mathrm{N}_{1} & 1 & 1 & 1\end{array}\right] \mathrm{I}^{s}$ & 3.17 & - & $4.563(1)$ \\
\hline$\left[\mathrm{NR}_{4}\right] \mathrm{I}(\mathrm{R}>\mathrm{Me})^{q, t}$ & $3.13(3)$ & $3.13(4)$ & $\begin{array}{l}4.645(2) \\
4.64-5.05\end{array}$ \\
\hline
\end{tabular}

${ }^{a}$ Distances (in $\AA$ ) averaged for all contacts shorter than the sum of Van der Waals (VdW) radii (refs. 53 and 54). ${ }^{b}$ These distances represent the closest approach of the halide ion to the phosphorus or nitrogen from each set of compounds considered, i.e. they are not average values; for data sets of more than one structure, the range of minimum distances is given in italics. ${ }^{b}$ Data retrieved from the Crystallographic Structural Database (CSD) are referred to by their six-letter code. ${ }^{d}$ \#UJIJAY. ${ }^{e}$ This work. ${ }^{f}$ \#XISCUX. ${ }^{g}\left[\mathrm{P}_{\text {cyclo-4 }} \text { cyclo-4 }\right]^{+}=$5-phosphoniaspiro[4.4]nonane; \#EFOWUR. ${ }^{h}\left[\mathrm{P}_{\text {cyclo-4 } 22}\right]^{+}=$1,1-diethylphospholanium; \#DUBNAP. ${ }^{i}$ \#LIVWUJ, \#LIVWUJ01. ${ }^{j}\left[\mathrm{C}_{n} \text { mpyrr }\right]^{+}=1$-alkyl-1-methylpyrrolidinium; $\left[\mathrm{C}_{n} \text { mpip }\right]^{+}=$ 1-alkyl-1-methylpiperidinium. ${ }^{k}$ \#HIVROT, \#HIVROT01. ${ }^{l}\left[\mathrm{~N}_{\text {cyclo-4 cyclo-4 }}\right]^{+}=$ 5-azoniaspiro[4.4]nonane; \#IWIKUU. ${ }^{m}$ \#KUKSOZ, \#YUHFUD, \#YUHGAK. ${ }^{n}$ \#ZZZUQO03. ${ }^{\circ}$ \#BIFDAV, \#CANYOG, \#CEMEBR01, \#OJIGOD, \#OJIGOD01. ${ }^{p}$ \#CANYUM, \#RABTIX, \#TPRAMB, \#TUDQEO, \#XISDIM. ${ }^{q} \mathrm{R}=$ linear alkyl chain longer than methyl. $r$ \#QOPZOK, \#REKYOW, \#WAWHIM. ${ }^{s}$ \#QQQCVG01. ${ }^{t}$ \#ALEXEU, \#CANZAT, \#CANZEX, \#CAVXEC01, \#HEVMEA, \#RABTET01, \#XISDOS.

Average $\mathrm{H} \cdots \mathrm{X}$ distances for all contacts shorter than the sum of Van der Waals radii are listed in Table $\mathbf{5}$ for both ammonium and phosphonium crystal structures. The overall trend suggests 5 that some degree of hydrogen bonding is present in the structures, decreasing in the $\mathrm{F}^{-}>\mathrm{Cl}^{-}>\mathrm{Br}^{-}>\mathrm{I}^{-}$order. This is consistent with previous statistical studies performed on all structures in the CSD. ${ }^{54}$ In the case of iodide, mean $\mathrm{H} \cdots \mathrm{I}$ distances were found in the 2.97-3.18 A range, only marginally below the Van der Waals 10 cut-off distance $(3.18 \AA)$, thus indicating very weak hydrogen bonding.

The effect of increasing anion size in the $\mathrm{F}^{-}<\mathrm{Cl}^{-}<\mathrm{Br}^{-}<\mathrm{I}^{-}$ order is clearly reflected in the increasing $\mathrm{E} \cdots \mathrm{X}(\mathrm{E}=\mathrm{N}$ or $\mathrm{P}$, $\mathrm{X}=$ halide) distances, as seen in Table 5. For example, by 15 inspecting the minimum $\mathrm{N} \cdots \mathrm{X}$ distances for tetraalkylammonium halides, an increase in the shortest interionic separations ( $c a$. 3.89, 4.06 and $4.30 \AA$ for $\mathrm{Cl}^{-}, \mathrm{Br}^{-}$and $\mathrm{I}^{-}$, respectively) is evident with increasing anion size, as expected. As for tetraalkylphosphonium salts, a similar trend is observed, with the exception of $\left[\mathrm{P}_{10} 101010\right] \mathrm{Br}$ (vide infra), for which the minimum $\mathrm{P}$... Br distance is unexpectedly long (ca. $4.86 \AA$ ).

For $\left[\mathrm{P}_{44} 4_{3}\right] \mathrm{Cl}$, the shortest $\mathrm{P} \cdots \mathrm{Cl}$ distance found is $c a .4 .0 \AA$, $0.45 \AA$ above the sum of the corresponding Van der Waals radii. The closest phosphorus and bromine atoms in $\left[\mathrm{P}_{10} 101010\right.$ 10 $\mathrm{Br}$ are ${ }_{25}$ ca. $4.86 \AA$ apart, more than $1.2 \AA$ longer than the sum of the Van der Waals radii (this is comparable to the $\mathrm{N} \cdots \mathrm{Br}$ contact in the

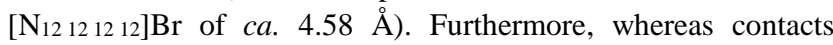
between chloride anions and hydrogen atoms in the $\alpha$ positions in the cation were found for $\left[\mathrm{P}_{4443}\right] \mathrm{Cl}$, only contacts between bromide anions and hydrogen atoms in the $\beta$ positions were observed for $\left[\mathrm{P}_{10} 101010 \mathrm{l} 10 \mathrm{Br}\right.$. As the linear alkyl chains increase in length, two competing effects are realised: (i) the electrostatic attraction between the cation and the anion is reduced and (ii) the Van der Waals repulsive forces are increased. In other words, 35 when the chain lengths are below say hexyl, the structure is best described as a simple salt dominated by Coulombic forces, and when the chain lengths above say octyl the structure has a much more covalent nature. In addition the shorter (and disordered) butyl and propyl chains in $\left[\mathrm{P}_{44_{4}}\right] \mathrm{Cl}$ are more flexible, as 40 opposed to the rigid, highly ordered (all-anti conformation) decyl chains in $\left[\begin{array}{llll}\mathrm{P}_{10} & 10 & 10 & 10\end{array}\right] \mathrm{Br}^{45}$

Unfortunately, no structures (with 3D coordinates available) for tetraalkylphosphonium iodides (where the alkyl groups are linear) were found in the CSD. However, some crystal structures 45 of alicyclic phosphonium salts were found. ${ }^{46-48}$ In these structures, the iodide anions are relatively close to the phosphorus atom (see Table 5 for minimum P...I distances). If we examine the pair of iodide salts containing spiro and single heterocyclic substituents, the iodide can approach closer to the centre of the 50 spiro compound (4.53 vs. $4.63 \AA$ ). It would therefore be expected that the unconstrained tetraalkylphosphonium iodide would have a separation of about $4.73 \AA$, much shorter than the analogous bromide at $4.86 \AA$. In spite of the larger ionic volume of iodide as compared to bromide, the former appears to approach much 55 closer to the phosphorus atom than the latter.

Data for tetraalkylammonium halides further confirm the aforementioned effects of the alkyl substitution and/or the ring strain on the interionic separation. For example, the shortest $\mathrm{N} \cdots \mathrm{Cl}$ distances in $\left[\mathrm{N}_{22} 2_{2}\right] \mathrm{Cl}$ and $\left[\mathrm{C}_{3}\right.$ mpyrr $] \mathrm{Cl}\left(\left[\mathrm{C}_{3} \text { mpyrr }\right]^{+}=\right.$ 60 1-methyl-1-propylpyrrolidinium) are significantly different ( $c a$. 4.36 and $4.28 \AA$ ), despite the fact that each cation type contains the same number of carbon atoms. This demonstrates that the presence strained rings around the central atom allows for a closer approach of the halide anion. These trends are further ${ }_{65}$ confirmed for bromide and iodide salts, where sufficiently large amount of crystal structures were found in the CSD. These data have been arranged into groups owing to the nature of the $N$-alkyl substituents (spiro vs. cyclic vs. non-cyclic, and for non-cyclic, according to the number of $N$-methyl substituents), as can be seen

70 in Table 5. For cyclic cations, the minimum N...halide distances found reveal the same trend as discussed above for phosphonium iodides: the larger the ring strain, the closer the halide approach to the nitrogen atom. For example, whereas for the spiro

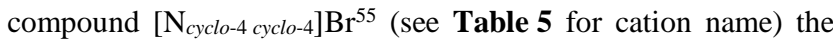
75 bromide anion is as close as $4.120 \AA$, the range of minimum 
$\mathrm{N} \cdots \mathrm{Br}$ distances for systems containing only one cycle, namely $\left[\mathrm{C}_{n}\right.$ mpyrr $] \mathrm{Br}$ salts, ${ }^{56,57}$ is $4.23-4.26 \AA$. In the case of non-cyclic tetraalkylammonium bromides, the bromide anion is found at minimum distances between 4.06 and $4.37 \AA$ from the nitrogen 5 atom for cations bearing methyl substituents, whereas this separation is increased to a 4.36-4.94 $\AA$ range for cations with

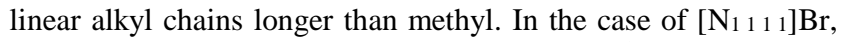
the shortest $\mathrm{N} \cdots \mathrm{Br}$ distance is found at $4.373 \AA{ }^{58},{ }^{5}$ a separation noticeably longer than for other $N$-methyl containing salts (4.06${ }_{10} 4.10 \AA$ range, see Table 5). The more sterically compact and symmetrical tetramethylammonium cation prevents the halide ion approaching too close to the nitrogen, compared to the situation with longer more flexible chains.

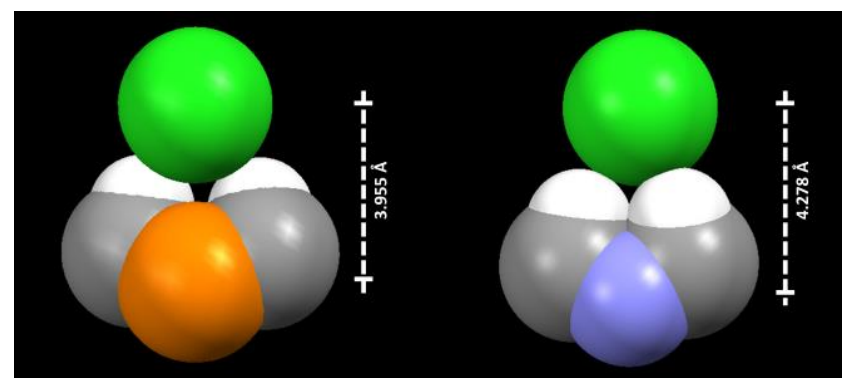

15 Fig.12 Space-filling (1 Van der Waals radii) views of $\mathrm{E}(\mathrm{CH})_{2} \cdot \mathrm{X}$ moieties $(\mathrm{E}=\mathrm{P}$ or $\mathrm{N})$ in the crystal structures of $\left[\mathrm{P}_{4443}\right] \mathrm{Cl}$ (right) and $\left[\mathrm{N}_{2222}\right] \mathrm{Cl}$ (left). The rest of the cation molecules have been omitted for clarity. Orange $=$ phosphorus, grey $=$ carbon, white $=$ hydrogen, blue $=$ nitrogen and green $=$ chlorine. $\mathrm{E} \cdots \mathrm{Cl}$ distances are schematically represented by dashed white lines.

Finally, by comparing the $\mathrm{E} \cdots \mathrm{Cl}$ distances in the structures of $\left[\mathrm{P}_{44} 4_{3}\right] \mathrm{Cl},\left[\mathrm{N}_{22} 2_{2}\right] \mathrm{Cl}$ and $\left[\mathrm{C}_{3} \mathrm{mpyrr}\right] \mathrm{Cl}$ (see Table 5), a further, more subtle, pattern is observed. In the structures of $\left[\mathrm{N}_{2} 2_{22}\right] \mathrm{Cl}$ (two polymorphs), the shortest $\mathrm{N} \cdots \mathrm{Cl}$ distances are $c a .4 .28$ and ${ }_{25} 4.36 \AA$. In the case of $\left[\mathrm{C}_{3}\right.$ mpyrr $] \mathrm{Cl}$ (again two polymorphs), the shortest $\mathrm{N} \cdots \mathrm{Cl}$ separations are $c a .3 .89$ and $3.91 \AA\{c f . \mathrm{P} \cdots \mathrm{Cl}$ at $3.955 \AA$ in $\left.\left[\mathrm{P}_{44} 4_{3}\right] \mathrm{Cl}\right\}$, thus presenting a lower steric hindrance than either $\left.\left[\mathrm{N}_{2} 2_{2}\right]_{2}\right]^{+}$or $\left[\mathrm{P}_{44} 4_{3}\right]^{+}$. This fact might initially look counterintuitive, given the smaller size of nitrogen as compared 30 to phosphorus. However, a close examination of the environments around nitrogen and phosphorus atoms in $\left[\mathrm{N}_{22} 2_{2}\right] \mathrm{Cl}$ and $\left[\mathrm{P}_{4443}\right] \mathrm{Cl}$ revealed that the smaller size of nitrogen is responsible for a relatively compact $\mathrm{N}\left(\mathrm{CH}_{2}\right)_{4}$ central moiety in the former, as illustrated in Figure 12, where the atoms 35 occupy their full Van der Waals volume. The $\mathrm{H}_{\alpha} \cdots \mathrm{H}_{\alpha^{\prime}}$ separation in the ammonium cation (for those hydrogen atoms shown in Figure 12) is $2.29 \AA$, effectively blocking the approach of the chloride anion to the nitrogen atom despite the presence of hydrogen bonding. In contrast, the $\mathrm{H}_{\alpha} \cdots \mathrm{H}_{\alpha^{\prime}}$ separation in the 40 phosphonium cation (also for those hydrogen atoms shown in Figure 12) is $2.69 \AA$, allowing a much closer approach of the chloride ion despite (or because of) the longer carbon-phosphorus bond. In other words, the more open structure around the phosphorus allows a deeper penetration of the halide ion through 45 the protective "shrubbery" of the alkyl groups than is permitted by the closed structure around the nitrogen atom. These crystallographic observations were anticipated by an elegant computational study by Hunt and co-workers. ${ }^{59}$

\section{${ }_{50}$ DSC and TGA measurements}

The melting $\left(T_{\mathrm{m}}\right)$ and glass transition temperatures $\left(T_{\mathrm{g}}\right)$ for $\left[\mathrm{P}_{444 \mathrm{n}}\right] \mathrm{Cl}$ were measured by differential scanning calorimetry, see Table 6. The trends of $T_{\mathrm{m}}$ and $T_{\mathrm{g}}$ as a function of $n$ are illustrated in Figure 13. All compounds (with the one exception, $\left.55\left[\mathrm{P}_{44} 4_{10}\right] \mathrm{Cl}\right)$, exhibited distinct melting points with four of them very close to, or just below, room temperature, see Figures 14(A) to $\mathbf{1 4}(\mathrm{C})$. Ionic liquids, with $n=1$ or $5-14$, also displayed glass transitions. Compounds with $n=1,5$ or 7 exhibited crystallisation above their glass transitions, see Fig. 14(A). ${ }_{60}\left[\mathrm{P}_{444}{ }_{10}\right] \mathrm{Cl}$, as the only exception, formed a glass at $-50.4{ }^{\circ} \mathrm{C}$ with no apparent freezing or melting transitions see Fig. 14(D).

Table 6 Decomposition temperatures, $T_{\mathrm{d}}$ for $\left[\mathrm{P}_{88_{8}}\right] \mathrm{Cl}$ were determined by dynamic TGA. $T_{\mathrm{m}}$ and $T_{\mathrm{g}}$ obtained by DSC are reported along with the 65 enthalpies of fusion, $\Delta H_{\text {fus }}$, and enthalpies of glass transition, $\Delta H_{\text {glass-1. }}$.

\begin{tabular}{cccccc}
\hline $\boldsymbol{n}$ & $\boldsymbol{T}_{\mathbf{m}} /{ }^{\circ} \mathbf{C}$ & $\Delta \boldsymbol{H}_{\text {fus }} / \mathbf{J} \mathbf{g}^{-\mathbf{1}}$ & $\boldsymbol{T}_{\mathrm{g}} /{ }^{\circ} \mathbf{C}$ & $\Delta \boldsymbol{H}_{\text {glass-- }} / \mathbf{J ~ g ~}^{-\mathbf{1}}$ & $\boldsymbol{T}_{\mathrm{d}} /{ }^{\circ} \mathbf{C}$ \\
\hline $\mathbf{1}$ & 20.4 & 9.66 & -52.7 & 1.07 & 311 \\
$\mathbf{2}$ & 70.1 & 32.16 & - & - & 332 \\
$\mathbf{3}$ & 78.0 & 58.75 & - & - & 335 \\
$\mathbf{4}$ & 70.6 & 63.10 & - & - & 352 \\
$\mathbf{5}$ & 47.6 & 21.74 & -40.4 & 0.01 & 361 \\
$\mathbf{6}$ & 24.2 & 2.78 & -49.9 & 0.85 & 357 \\
$\mathbf{7}$ & 53.3 & 75.43 & -41.2 & 1.37 & 358 \\
$\mathbf{8}$ & 19.4 & 0.23 & -45.5 & 1.05 & 358 \\
$\mathbf{1 0}$ & - & - & -50.4 & 1.31 & 338 \\
$\mathbf{1 2}$ & 22.8 & 49.40 & -62.2 & 1.04 & 352 \\
$\mathbf{1 4}$ & 38.9 & 65.60 & -58.8 & 0.64 & 345 \\
\hline
\end{tabular}

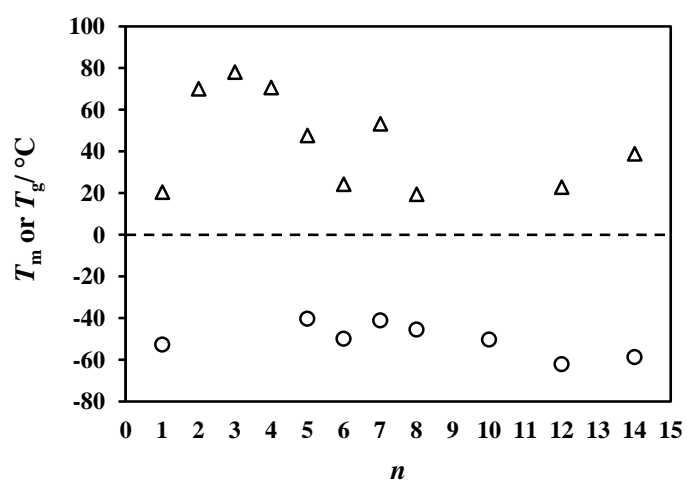

Fig. 13 Melting $(\Delta)$ and glass transition (०) temperatures, $T_{\mathrm{m}}$ and $T_{\mathrm{g}}$, respectively, as a function of the number of carbons, $n$, in the fourth alkyl 70
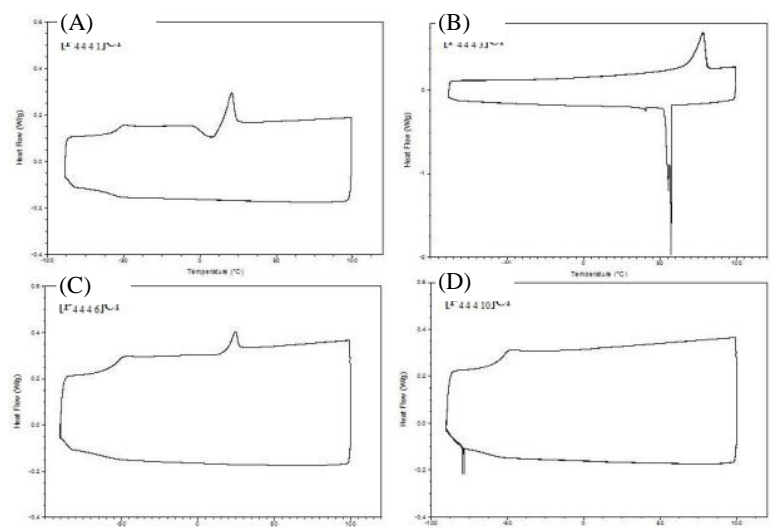
Fig. 14 DSC scans of selected compounds representing typical DSC curves for whole series of $\left[\mathrm{P}_{444}\right] \mathrm{Cl}$ ionic liquids, (A) $\left[\mathrm{P}_{4441}\right] \mathrm{Cl}$, (B) $\left[\mathrm{P}_{4443}\right] \mathrm{Cl},(\mathrm{C})\left[\mathrm{P}_{4446}\right] \mathrm{Cl}$ and (D) $\left[\mathrm{P}_{44410}\right] \mathrm{Cl}$.

5 The thermal decomposition temperatures are listed in Table 6, for $\left[\mathrm{P}_{444 n}\right] \mathrm{Cl}$. While the decomposition temperatures of phosphonium ionic liquids vary with the counter ion, ${ }^{7}$ the alkyltributylphosphonium chlorides under investigation here appear to show dynamic thermal stability around $342 \pm 17{ }^{\circ} \mathrm{C}$ 10 (four TGA scans are shown in Figure 15, as examples).

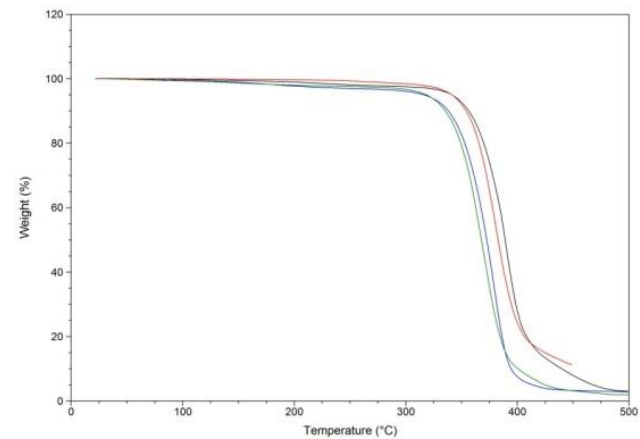

Fig. 15 A typical TGA curves for $\left[\mathrm{P}_{444 n}\right] \mathrm{Cl}$, examples of $\left[\mathrm{P}_{4442}\right] \mathrm{Cl}$ (black line), $\left[\mathrm{P}_{4444}\right] \mathrm{Cl}$ (blue line), $\left[\mathrm{P}_{4447}\right] \mathrm{Cl}$ (red line) and $\left[\mathrm{P}_{44414}\right] \mathrm{Cl}$ (green line).

15 Figure 16 illustrates the trend of onset decomposition temperature as a function of $n$, which on average is increasing with increasing alkyl chain up to $n=5$.

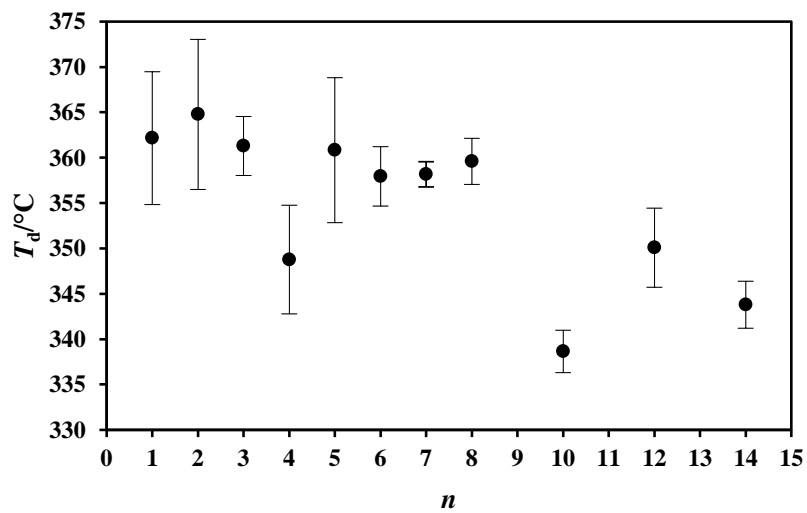

Fig. 16 Onset decomposition temperatures of $\left[\mathrm{P}_{444}\right] \mathrm{Cl}$ ionic liquids as a 20 function of $n$.

This reflects, as seen in the crystallographic section the greater resistance to the chloride ion approaching the $\alpha$ carbon atom. As the decomposition mechanism involves an $\mathrm{S}_{\mathrm{N}} 2$ reaction (reversing its formation from the free phosphine and 25 chloroalkane), the difficulty of approach of the chloride to the $\alpha$ carbon results in a more thermally stable material. For chain lengths where $n>6$ the distance of closest approach reaches a plateau, as does the thermal stability. As $n>8$ the cation becomes slightly less stable with the transparent anomaly at $n=10$, for 30 which we have no explanation.

Tsunashima et al. $^{3,60}$ studied two cations found in this work, $\left(\left[\mathrm{P}_{4441}\right]^{+}\right.$and $\left.\left[\mathrm{P}_{4448}\right]^{+}\right)$, paired with dicyanamide and bistriflamide. These ionic liquids exhibited lower melting points and approximately $40{ }^{\circ} \mathrm{C}$ higher decomposition temperatures than 35 their chloride analogues, as the bulky $\left[\mathrm{N}(\mathrm{CN})_{2}\right]^{-}$and $\left[\mathrm{NTf}_{2}\right]^{-}$ anions are unable to penetrate so close to the inner carbon atoms, and are also less nucleophilic than the chloride ion.

\section{Density and molar volume}

Density measurements upon $\left[\mathrm{P}_{444 n}\right] \mathrm{Cl}$, where $n=1,6,8,10$ and 4012 (selected as the ones liquid at room temperature) were carried out over a broad range of temperatures $(293.15<T / \mathrm{K}<363.15)$ at atmospheric pressure, and data are reported along with the corresponding molar volume, $V_{\mathrm{m}}$, Table 7 . The repeatability of the density measurements was better than $5 \times 10^{-5} \mathrm{~g} \mathrm{~cm}^{-3}$.

45 These densities are in the range of 0.87 to $0.96 \mathrm{~g} \mathrm{~cm}^{-3}$ over a temperature range of 293.15 to $363.15 \mathrm{~K}$. All the studied ionic liquids have densities less than water and all decrease with increasing $n$, see Figure 17, and with increasing $T$, see Figure 18.

50

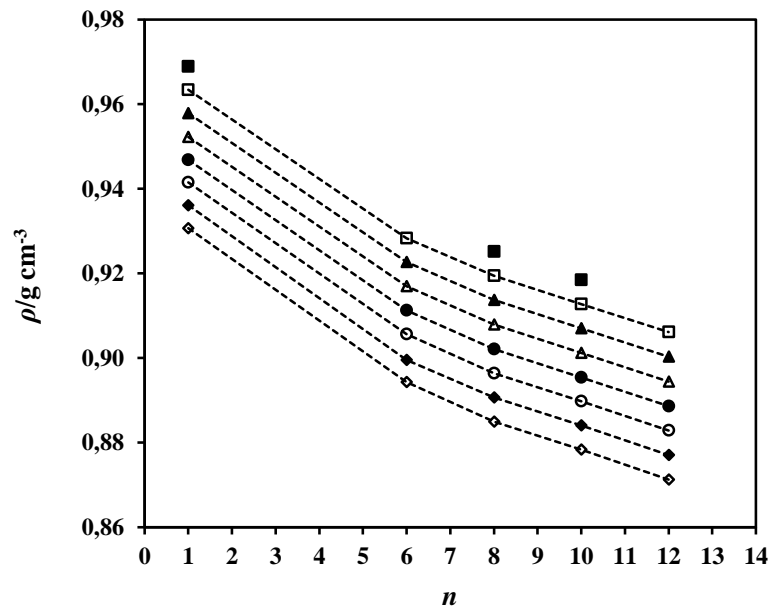

Fig.17 Experimental densities of $\left[\mathrm{P}_{444 n}\right] \mathrm{Cl}$ ionic liquids at $293 \mathrm{~K}(\mathbf{\bullet}), 303$ $\mathrm{K}(\square), 313 \mathrm{~K}(\boldsymbol{\Delta}), 323 \mathrm{~K}(\Delta), 333 \mathrm{~K}(\bullet), 343 \mathrm{~K}(\circ), 353 \mathrm{~K}(\bullet)$ and $363 \mathrm{~K}$ $(\diamond)$ as a function $n$.

55 Experimental density data were fitted into the extended Ye and Shreeve equation ${ }^{61}$ proposed by Gardas and Couthino, ${ }^{62}$ which is applicable over a wide range of temperatures 273 - $393 \mathrm{~K}$, and pressures, 0.10 - $100 \mathrm{MPa}$, according to Eq. (1):

60

$$
\rho_{I L}(T, P)=M / \mathrm{N}_{\mathrm{A}} V(a+b T+c P)
$$

where $M$ is the formula mass in $\mathrm{g} \mathrm{mol}^{-1}, \mathrm{~N}_{\mathrm{A}}$ is Avogadro's number, $V^{\text {molecular }}$ is molecular volume in units of $1 \times 10^{-27} \mathrm{~cm}^{3}, T$ is the temperature in $\mathrm{K}$, and $P$ is the pressure in $\mathrm{MPa}$. 


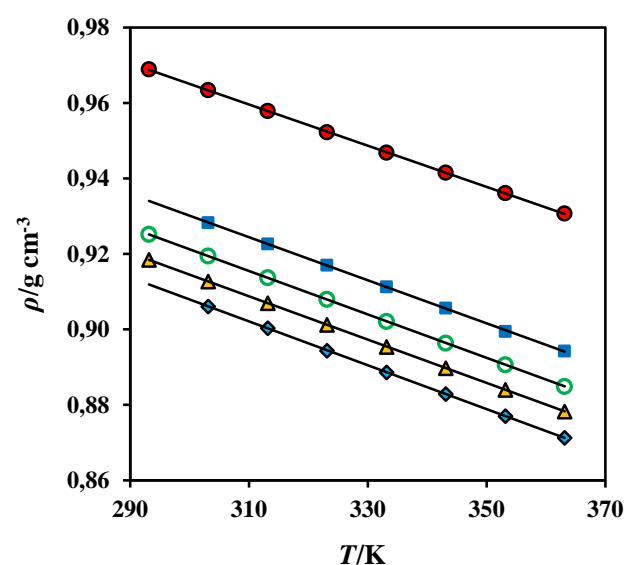

Fig. 18 Experimental density as a function of temperature for the $\left[\mathrm{P}_{444 n}\right] \mathrm{Cl}$ ionic liquids series where $n=1(\bullet), 6(\bullet), 8(\circ), 10(\triangle)$ and 12 $(\diamond)$.The lines correspond to the linear fit of experimental results obtained in this work $\left(0.99993 \leq R^{2} \leq 1\right)$.

The values of the coefficients $a, b$ and $c$ were estimated by Gardas and Coutinho $^{62}$ as $0.80050 \pm 0.00023$, $(6.6520 \pm 0.0069) \times 10^{-4} \mathrm{~K}^{-1}$, and $(-5.919 \pm 0.024) \times 10^{-6} \mathrm{MPa}^{-1}$, 10 respectively, by fitting Eq.(1) to the previously published experimental pressure-volume-temperature $(P V T)$ data of ionic liquids (imidazolium, pyridinium, pyrrolidinium and phosphonium based). ${ }^{63,64}$

The densities of alkyltributylphosphonium ionic liquids were 15 estimated according to Eq. (1) with the molecular volumes of ions and groups taken from previously reported values ${ }^{10,11,62,65}$ where available.

The calculated density $\rho_{\text {calc }}$ of the studied ionic liquids displays a good agreement with the corresponding experimental density ${ }_{20} \rho_{\exp }$, where (see Figure 19):

$$
\begin{aligned}
\rho_{\text {calc }}=(0.9982 \pm 0.0015) \rho_{\exp } \\
\left(R^{2}=0.9964 \text { at a } 95 \% \text { level of confidence }\right)
\end{aligned}
$$

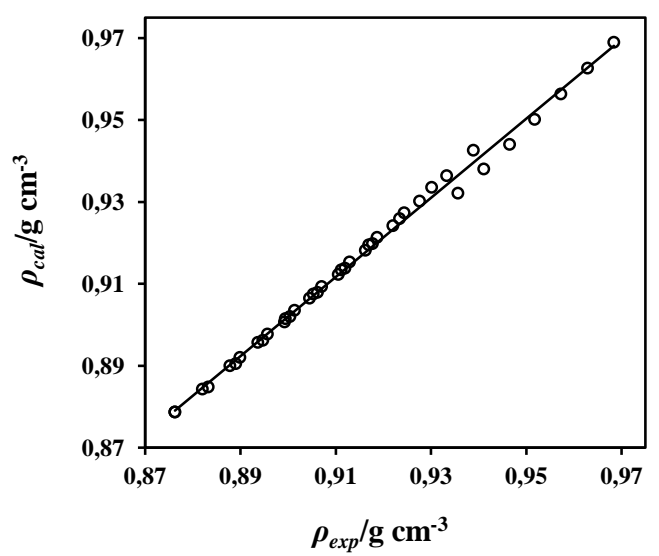

25 Fig. 19 Linear relationship between experimental and calculated density of herein studied ionic liquids at temperatures $T=293.15-363.15 \mathrm{~K}$, using the Eq.1

Table 7 Comparisons between experimental density $\rho / \mathrm{g} \mathrm{cm}^{-3}$ and molar volume data for $\left[\mathrm{P}_{444 n}\right] \mathrm{Cl}$ ionic liquids measured at temperatures $T=$ 30 293.15-363.15 K. Calculated density values were obtained from Eq.(1). $\Delta V_{\mathrm{m}}$ values represent the difference (cal - exp) between $V_{\mathrm{m}}$ values and

\begin{tabular}{|c|c|c|c|c|c|c|}
\hline $\begin{array}{l}T / \\
\mathbf{K} \\
\end{array}$ & $\begin{array}{c}\rho_{\text {exp }} / \\
\mathrm{g} \mathrm{cm}^{-3} \\
\end{array}$ & $\begin{array}{c}\rho_{\mathrm{cal}} / \\
\mathrm{g} \mathrm{cm}^{-3}\end{array}$ & $\begin{array}{c}\text { Dev }^{\mathrm{a}} / \\
\%\end{array}$ & $\begin{array}{c}\left(V_{\mathrm{m}}\right)_{\exp } / \\
\mathrm{cm}^{3} \mathrm{~mol}^{-1} \\
\end{array}$ & $\begin{array}{c}\left(V_{\mathrm{m}}\right)_{\mathrm{cal}} / \\
\mathrm{cm}^{3} \mathrm{~mol}^{-1}\end{array}$ & $\begin{array}{c}\Delta V_{\mathbf{m}}^{\mathrm{b}} / \\
\mathrm{cm}^{3} \mathrm{~mol}^{-1}\end{array}$ \\
\hline \multicolumn{7}{|c|}{$\left[\mathrm{P}_{4441}\right] \mathrm{Cl}$} \\
\hline 303.15 & 0.96340 & 0.9640 & 0.16 & 262.14 & 256.15 & -3.47 \\
\hline 313.15 & 0.95786 & 0.9576 & 0.06 & 263.66 & 258.68 & -2.46 \\
\hline 323.15 & 0.95225 & 0.9514 & -0.02 & 265.21 & 26.20 & -1.49 \\
\hline 333.15 & 0.96820 & 0.9452 & -0.09 & 266.73 & 263.73 & -0.48 \\
\hline 343.15 & 0.94151 & 0.9391 & -0.17 & 268.24 & 266.26 & 0.54 \\
\hline 353.15 & 0.93611 & 0.9330 & -0.26 & 269.79 & 268.78 & 1.52 \\
\hline 363.15 & 0.93069 & 0.9271 & -0.33 & 271.36 & 271.31 & 2.48 \\
\hline \multicolumn{7}{|c|}{$\left[\mathrm{P}_{4446}\right] \mathrm{Cl}$} \\
\hline 293.15 & - & - & - & - & - & - \\
\hline 303.15 & 0.92830 & 0.9313 & 0.33 & 347.60 & 344.86 & -2.75 \\
\hline 313.15 & 0.92264 & 0.9252 & 0.28 & 349.74 & 347.79 & -1.94 \\
\hline 323.15 & 0.91699 & 0.9191 & 0.23 & 351.89 & 350.73 & -1.17 \\
\hline 333.15 & 0.91125 & 0.9132 & 0.21 & 354.11 & 353.66 & -0.45 \\
\hline 343.15 & 0.90560 & 0.9072 & 0.18 & 356.32 & 356.59 & 0.28 \\
\hline 353.15 & 0.89950 & 0.9014 & 0.21 & 358.73 & 359.53 & 0.79 \\
\hline 363.15 & 0.89428 & 0.8957 & 0.15 & 360.83 & 362.46 & 1.63 \\
\hline \multicolumn{7}{|c|}{$\left[\mathrm{P}_{4448}\right] \mathrm{Cl}$} \\
\hline 293.15 & 0.92516 & 0.9285 & 0.36 & 379.11 & 376.23 & -2.88 \\
\hline 303.15 & 0.91942 & 0.9224 & 0.32 & 381.48 & 379.33 & -2.15 \\
\hline 313.15 & 0.91368 & 0.9163 & 0.28 & 383.88 & 382.43 & -1.45 \\
\hline 323.15 & 0.90792 & 0.9103 & 0.26 & 386.31 & 385.52 & -0.79 \\
\hline 333.15 & 0.90211 & 0.9044 & 0.25 & 388.80 & 388.62 & -0.18 \\
\hline 343.15 & 0.89639 & 0.8985 & 0.24 & 391.28 & 391.72 & 0.44 \\
\hline 353.15 & 0.89067 & 0.8927 & 0.23 & 393.79 & 394.81 & 1.02 \\
\hline 363.15 & 0.88493 & 0.8870 & 0.24 & 396.35 & 397.91 & 1.56 \\
\hline \multicolumn{7}{|c|}{$\left[\mathrm{P}_{44410}\right] \mathrm{Cl}$} \\
\hline 293.15 & 0.91844 & 0.9209 & 0.27 & 412.43 & 410.54 & -1.89 \\
\hline 303.15 & 0.91272 & 0.9148 & 0.23 & 415.01 & 413.80 & -1.21 \\
\hline 313.15 & 0.90698 & 0.9088 & 0.20 & 417.64 & 417.06 & -0.58 \\
\hline 323.15 & 0.90122 & 0.9028 & 0.18 & 420.31 & 420.32 & 0.01 \\
\hline 333.15 & 0.89543 & 0.8970 & 0.17 & 423.03 & 423.58 & 0.56 \\
\hline 343.15 & 0.88974 & 0.8912 & 0.16 & 425.73 & 426.84 & 1.11 \\
\hline 353.15 & 0.88402 & 0.8854 & 0.16 & 428.49 & 430.10 & 1.62 \\
\hline 363.15 & 0.87831 & 0.8798 & 0.17 & 431.27 & 433.36 & 2.09 \\
\hline \multicolumn{7}{|c|}{$\left[P_{44412}\right] \mathrm{Cl}$} \\
\hline 293.15 & - & - & - & - & - & - \\
\hline 303.15 & 0.90614 & 0.9084 & 0.28 & 448.98 & 448.28 & -0.71 \\
\hline 313.15 & 0.90030 & 0.9024 & 0.24 & 451.89 & 451.70 & -0.20 \\
\hline 323.15 & 0.89443 & 0.8965 & 0.23 & 454.86 & 455.12 & 0.26 \\
\hline 333.15 & 0.88864 & 0.8907 & 0.23 & 457.82 & 458.54 & 0.72 \\
\hline 343.15 & 0.88286 & 0.8849 & 0.23 & 460.82 & 461.97 & 1.15 \\
\hline 353.15 & 0.87706 & 0.8792 & 0.25 & 463.87 & 465.39 & 1.52 \\
\hline 363.15 & 0.87126 & 0.8736 & 0.27 & 466.96 & 468.81 & 1.86 \\
\hline
\end{tabular}
molar volume data calculated using the fitting Eq.(6).
For the density prediction from molar volume, using Eq.(1), an average absolute deviation (AAD) of $0.23 \%$ with the maximum deviation (MD) $0.39 \%$ was observed for 37 density data points $\left(\mathrm{N}_{\mathrm{p}}\right)$, studied of 5 ionic liquids, where AAD is defined as, Eq. (2): 40

$$
A A D(\%)=\sum_{i=1}^{N_{p}}\left|\frac{\rho_{\text {calc }}-\rho_{\text {exp }}}{\rho_{\text {exp }}}\right| / N_{p}
$$

45 The volumetric behaviour of phosphonium ionic liquids can be expressed in terms of their molar volume, $V_{\mathrm{m}}=M / \rho$, where an expected increase of $V_{\mathrm{m}}$ with increasing temperature is observed, see Figure 20. $V_{\mathrm{m}}$ as a function of $n$ exhibits a quasi-linear trend for each represented temperature, Figure 21. 


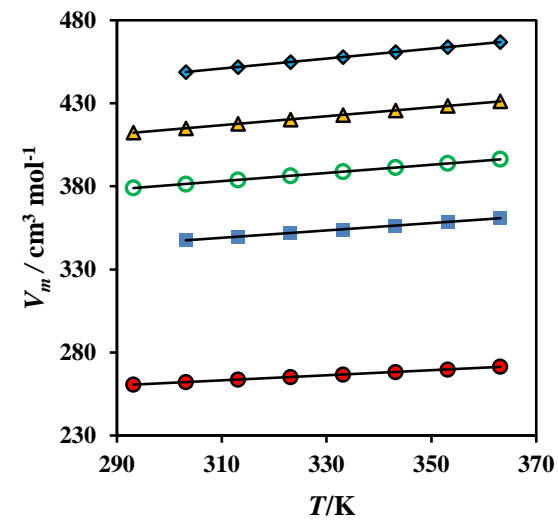

Fig. 20 Molar volumes as a function of temperature for the $\left[\mathrm{P}_{444}\right] \mathrm{Cl}$ ionic liquids series where $n=1(\bullet), 6(\bullet), 8(\circ), 10(\triangle)$ and $12(\diamond)$. The lines correspond to the linear fit of experimental results obtained in this work $\left(0.999735 \leq R^{2} \leq 0.99997\right)$.

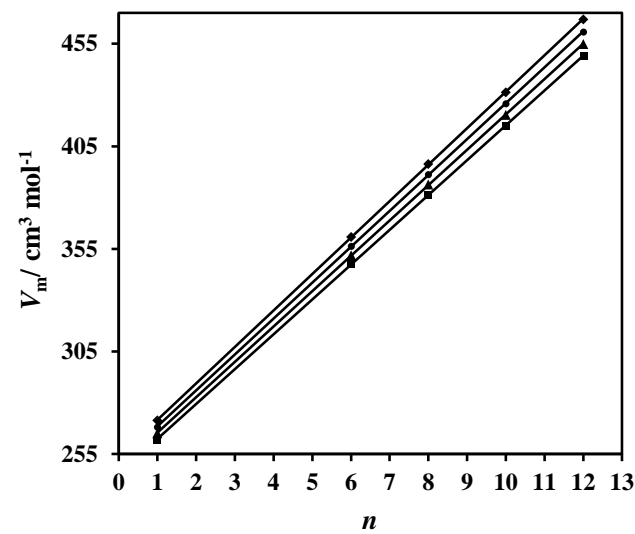

Fig. 21 Experimental molar volume of $\left[\mathrm{P}_{444 n}\right] \mathrm{Cl}$ ionic liquids as a function of $n$ for four temperatures. The isotherms are $293 \mathrm{~K}(\mathbf{\bullet}), 313 \mathrm{~K}$

$(\Delta), 333 \mathrm{~K}(\bullet)$ and $353 \mathrm{~K}(\bullet)$. The lines represent a linear fit of the results for each isotherm, $\left(0.99998 \leq R^{2} \leq 0.99999\right)$.

The molar volume $\left(V_{\mathrm{m}}\right)$ of an ionic liquid was defined simply as the sum of the effective molar volumes $\left(V^{*}\right)$ of the anion (a) and cation (c), Eq. (3):

$$
V_{m}=V_{c}^{*}+V_{a}^{*}
$$

15 The phosphonium ionic liquids presented in this study were divided into three groups, according to their structure, ${ }^{11}$ and each group is represented as a function of temperature according to the following Eq. (4):

$$
V_{m}\left(G_{i}\right)=A+B(T-273.15)
$$

${ }_{20} V_{\mathrm{m}}$ and is considered compose of contributions from $\left[\mathrm{P}_{1111}\right]^{+}$, $-\left(\mathrm{CH}_{2}\right)_{\mathrm{n}}$ - and $\mathrm{Cl}-$, hence the over all molar volume is represented by Eq. (5):

$$
V_{m}=\sum_{i=1}^{3} V_{m}\left(G_{i}\right)
$$

The parameters $A$ and $B$ can be obtained by a group contribution 25 method according to Eq.xy. Eq. (6) and Eq. (7):

$$
\begin{aligned}
& A=\sum_{i=1}^{3} n_{i} a_{i} \\
& B=\sum_{i=1}^{3} n_{i} b_{i}
\end{aligned}
$$

where $n_{i}$ is the number of groups of type $i$, and the parameters $a_{i}$ 30 and $b_{\text {i }}$ were previously estimated by Adamová and Gardas ${ }^{11}$ on $\left[\mathrm{P}_{8} 8_{8}{ }_{n}\right] \mathrm{Cl}$ ionic liquids (Table 8).

Calculated molar volumes are in an excellent agreement with the corresponding experimental values $\left(V_{\mathrm{m}}\right.$, exp, where:

$$
\left(V_{\mathrm{m}}\right)_{\text {, cal }}=(1.0003 \pm 0.0002) \cdot\left(V_{\mathrm{m}}\right)_{\text {,exp }}
$$$$
35
$$$$
\left(R^{2}=0.9997 \text { at } 95 \%\right. \text { level of confidence). }
$$

The relative deviations between the calculated and experimental data as a function of experimental molar volume for all data points are shown in Figure 22.

Table 8 Group contribution parameters associated with Eq. (5) ${ }^{\mathbf{1 1}}$ used to 40 predict the effective molar volume of the phosphonium ionic liquids as a function of temperature from 293.15 to $363.15 \mathrm{~K}$.

\begin{tabular}{ccc}
\hline & & \\
\hline $\boldsymbol{G}_{\boldsymbol{i}}$ & $\boldsymbol{a}_{\boldsymbol{i}} / \mathbf{c m}^{\mathbf{3}} \mathbf{~ m o l}^{-\mathbf{1}}$ & $\boldsymbol{b}_{\boldsymbol{i}} / \mathbf{c m}^{\mathbf{3}} \mathbf{~ m o l}^{-\mathbf{1}} \mathbf{K}^{\mathbf{1}}$ \\
\hline$\left[\mathbf{P}_{\mathbf{1 1 1 1}}\right]^{+}$ & 73.776 & 0.0840 \\
$-\mathbf{C H}_{\mathbf{2}^{-}}$ & 16.992 & 0.0082 \\
$\mathbf{C l}^{-}$ & 24.391 & 0.0954 \\
\hline
\end{tabular}

For 37 data points of five phosphonium ionic liquids, the overall AAD is $0.39 \%$ and MD is $0.80 \%$ (Table 9).

45 Table 9 AAD and MD observed for the molar volumes of studied phosphonium ionic liquids predicted using Eq.5.

\begin{tabular}{ccc}
\hline $\mathbf{n}$ & $\mathbf{A A D} / \%$ & MD/\% \\
\hline $\mathbf{1}$ & 0.67 & 1.32 \\
$\mathbf{6}$ & 0.45 & 1.04 \\
$\mathbf{8}$ & 0.34 & 0.76 \\
$\mathbf{1 0}$ & 0.27 & 0.48 \\
$\mathbf{1 2}$ & 0.21 & 0.40 \\
\hline
\end{tabular}

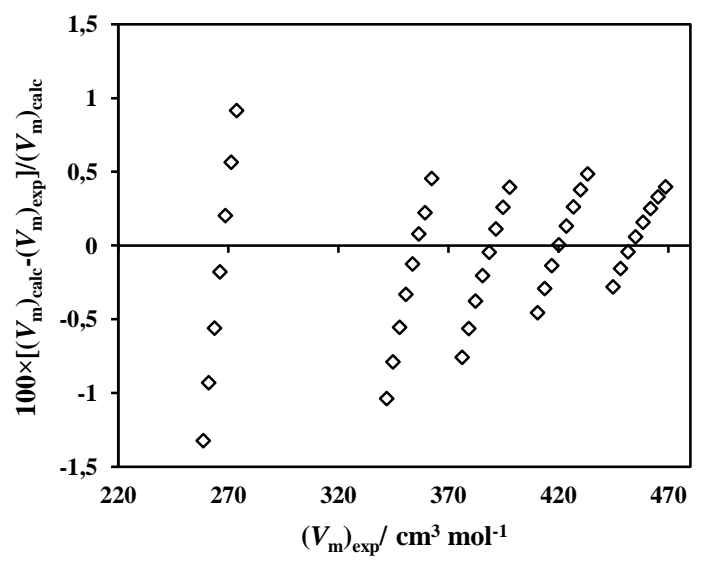

Fig. 22 The relative deviations between calculated, using an Eq.5 and the 50 experimental molar volumes as a function of experimental molar volumes for the phosphonium ionic liquids, where $n=1,6,8,10$ and 12 .

The deviations between calculated and experimental molar volumes are significantly higher, in contrast with $\left[\mathrm{P}_{8} 8_{8} n\right] \mathrm{Cl}$ 
compounds $(\mathrm{AAD}=0.13 \%$ and $\mathrm{MD}=0.28 \%),{ }^{11}$ which is most likely caused by much higher viscosity and mobility of $\left[\mathrm{P}_{444 n}\right] \mathrm{Cl}$ ionic liquids.

\section{Thermal expansion coefficient}

5 The evolution of the volumetric properties with temperature can be expressed by calculating the coefficient of thermal expansion, $\alpha_{\mathrm{p}}$, defined as, Eq. (8):

$$
\alpha_{p}=-[\partial \ln (\rho) / \partial T]_{p}=-a
$$

Plots of $\ln (\rho)$ as a function of temperature, Eq. (9) (fitting 10 equation parameters can be found in Table 10) for the studied ionic liquids have a quasi-linear fit, being almost parallel to each with similar thermal expansion coefficients, $\alpha_{\mathrm{p}}$, given in Table 10.

$$
\ln \left(\rho / \mathrm{cm}^{-3}\right)=a(T / m K)+b
$$

It has been already demonstrated by Tariq et al., ${ }^{66}$ that $\alpha_{\mathrm{p}}$ may slightly decrease with increasing temperature in the low- $T$ region and starts increasing (also mildly) in the high- $T$ domain. This phenomenon was reported on the homologous series of

${ }_{20}\left[\mathrm{C}_{n} \mathrm{mim}\right]\left[\mathrm{NTf}_{2}\right]$ studied over extended range of temperatures, but here, with the limited temperature range no such deviation was found.

Additionally, we observe a dependency of $\alpha_{\mathrm{p}}$ on chain length with calculated values lying between between $5.75 \times 10^{-4} \mathrm{~K}^{-1}$ and ${ }_{25} 6.52 \times 10^{-4} \mathrm{~K}^{-1}$, for $\left[\mathrm{P}_{444_{1}}\right] \mathrm{Cl}$ and $\left[\mathrm{P}_{444{ }_{12}}\right] \mathrm{Cl}$, respectively, see

Table 10, as found in previous studies. ${ }^{10,67,68}$ The comparison of these data with related systems will be published elsewhere. ${ }^{69}$

Table 10 Parameters of the linear fit, according to Eq. (10)

\begin{tabular}{ccc}
\hline $\boldsymbol{n}$ & $\boldsymbol{\alpha}_{\boldsymbol{P}}=\mathbf{- a} / \mathbf{K}^{-1} \times \mathbf{1 0}^{\mathbf{3}}$ & $\boldsymbol{b}$ \\
\hline $\mathbf{1}$ & 0.57467 & 0.136874 \\
$\mathbf{6}$ & 0.62610 & 0.115538 \\
$\mathbf{8}$ & 0.63546 & 0.108639 \\
$\mathbf{1 0}$ & 0.63870 & 0.102294 \\
$\mathbf{1 2}$ & 0.65240 & 0.099217 \\
\hline$\overline{\boldsymbol{\alpha}_{p}}=(\mathbf{6 . 2 5 4 6 4} \pm \mathbf{0 . 2 9 9 2 1}) \times \mathbf{1 0}^{-4} \mathbf{K}^{-1}$ \\
\hline
\end{tabular}

\section{${ }_{30}$ Viscosity}

The viscosity of ionic liquids is significantly influenced by the strength of both the van der Waals interaction forces and hydrogen bonding, but the chemical structure of the anion is known to have a strong influence, too. For example with 1,3-

35 dialkylimidazolium halides, their high viscosity has been ascribed to an extensive three-dimensional hydrogen bonding network. ${ }^{70}$ The viscosity has also being been shown to be a colligative property, decreasing as a function of the number of moles of solute (either water or organic molecules). ${ }^{71}$

40 Viscosities of $\left[\mathrm{P}_{444 n}\right] \mathrm{Cl}$, were measured at temperatures between 293.15 to $363.15 \mathrm{~K}$ ( see Table 11). Viscosities decrease with increasing $n$, as illustrated in Figure 23. Moreover, the results indicate that their viscosity decreases markedly with temperature increase. For example, for $\left[\mathrm{P}_{4} 4_{4} 1_{2}\right] \mathrm{Cl}$, increasing the 45 temperature by $10 \mathrm{~K}$ from (293.15 to 303.15$) \mathrm{K}$ decreases the viscosity by $57 \%$ and increasing it by $70 \mathrm{~K}$ lowers it by $98 \%$, (see Figure 24 and 25) .

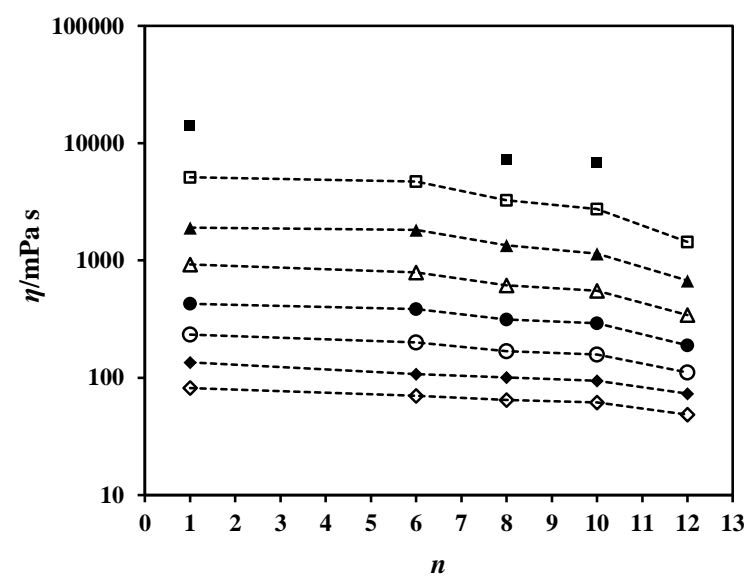

Fig. 23 Experimental viscosities of $\left[\mathrm{P}_{444 n}\right] \mathrm{Cl}$ ionic liquids at $293.15 \mathrm{~K}$ $50 \quad(\bullet), 303.15 \mathrm{~K}(\square), 313.15 \mathrm{~K}(\boldsymbol{\Delta}), 323.15 \mathrm{~K}(\Delta), 333.15 \mathrm{~K}(\bullet), 343.15 \mathrm{~K}$ $(\odot), 353.15 \mathrm{~K}(\bullet)$ and $363.15 \mathrm{~K}(\diamond)$ as a function of $n$.

The Vogel-Fulcher-Tammann (VFT) equation, Eq. (10), which has been successfully used to model the temperature dependence of ionic liquid viscosity for many years, ${ }^{72,73}$ was applied to the ${ }_{55}$ data in Table $\mathbf{1 0}$ and the fit is presented in Figures 24 and 25, and Table 11.

$$
\eta=A+\exp \left(B /\left(T-T_{0}\right)\right)
$$

where $\eta$ is the viscosity in $\mathrm{mPa}$ s units, $T$ is temperature $(\mathrm{K}), A, B$ and $T_{0}$ are adjustable parameters.

60 The ratio of parameters $B$ and $T_{0}, B / T_{0}$, is also known as the Angell strength parameter. The parameters $A, B$ and $T_{0}$ were optimised by minimising the following objective function $(\mathrm{OF})$, Eq. (11):

$$
O F=\sum_{i=1}^{N_{p}}\left[A+\frac{B}{\left(T-T_{0}\right)}-\ln \left(\rho_{\text {exp }}\right)\right]^{2} / N_{p}
$$

65

The AAD and MD values are presented in Table 12. The values of the parameter $T_{0}$ are between 105 to $160 \mathrm{~K}$.

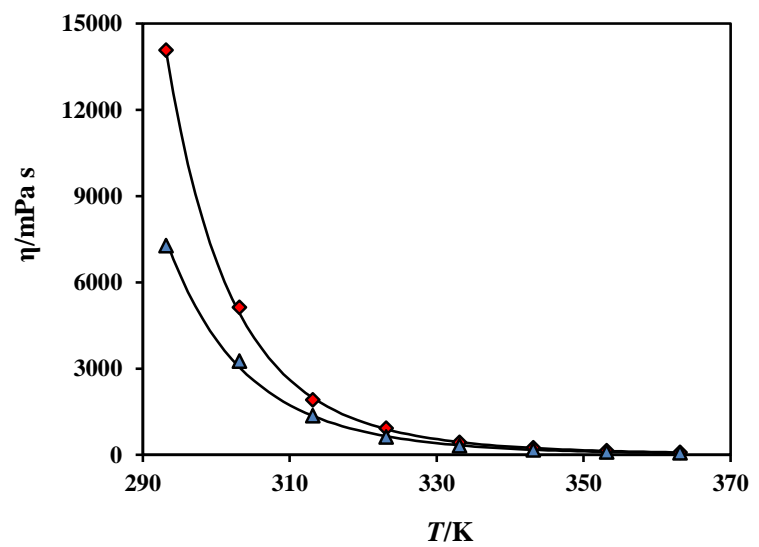

Fig. 24 Experimental viscosities as a function of temperature: $\left[\mathrm{P}_{4441}\right] \mathrm{Cl}$ $(\diamond)$ and $\left[\mathrm{P}_{4448}\right] \mathrm{Cl}(\boldsymbol{\Delta})$, fitted into VFT equation, Eq. 11. Fits are represented by solid lines. 
Table 11 Experimental viscosities $\left(\eta_{\text {exp }}\right)$ of phosphonium chlorides as a function of temperature at atmospheric pressure. Dev $^{\mathrm{a}}$ represents standard deviation of ten measurements perfomed with each sample at each given temperature. Calculated viscosities $\left(\eta_{\text {cal }}\right)$ were obtained from VFT 5 equation and $\mathrm{AAD}$ represents agreement between calculated and experimental data.

\begin{tabular}{|c|c|c|c|c|}
\hline $\begin{array}{l}T / \\
\mathbf{K}\end{array}$ & $\begin{array}{c}\eta_{\text {exp }} / \\
\text { mPa s }\end{array}$ & $\begin{array}{c}\text { Dev }^{\mathrm{a}} / \\
\%\end{array}$ & $\begin{array}{c}\eta_{\mathrm{cal}} / \\
\text { mPa s }\end{array}$ & $\underset{\%}{\mathbf{A A D}^{\mathbf{b}} /}$ \\
\hline \multicolumn{5}{|c|}{$\left[\mathbf{P}_{4441}\right] \mathrm{Cl}$} \\
\hline 293.15 & 14065.77 & 2.14 & 14061.85 & 0.03 \\
\hline 303.15 & 5123.50 & 2.03 & 4925.49 & 3.86 \\
\hline 313.15 & 1904.94 & 0.91 & 1978.55 & 3.86 \\
\hline 323.15 & 924.50 & 0.97 & 888.78 & 3.86 \\
\hline 333.15 & 427.00 & 0.92 & 437.91 & 2.56 \\
\hline 343.15 & 233.20 & 1.33 & 233.10 & 0.04 \\
\hline 353.15 & 135.30 & 2.27 & 132.45 & 2.11 \\
\hline 363.15 & 81.70 & 3.01 & 79.57 & 2.61 \\
\hline \multicolumn{5}{|c|}{$\left[\mathrm{P}_{4446}\right] \mathrm{Cl}$} \\
\hline 293.15 & - & - & - & - \\
\hline 303.15 & 4710.30 & 1.27 & 4631.80 & 1.67 \\
\hline 313.15 & 1815.00 & 1.63 & 1813.06 & 0.11 \\
\hline 323.15 & 788.61 & 1.76 & 795.38 & 0.86 \\
\hline 333.15 & 386.23 & 3.09 & 383.47 & 0.72 \\
\hline 343.15 & 200.08 & 3.06 & 200.08 & 0.00 \\
\hline 353.15 & 107.30 & 1.85 & 111.62 & 4.03 \\
\hline 363.15 & 70.14 & 3.51 & 65.92 & 6.01 \\
\hline \multicolumn{5}{|c|}{$\left[\mathrm{P}_{4448}\right] \mathrm{Cl}$} \\
\hline 293.15 & 7269.56 & 1.19 & 7486.04 & 2.98 \\
\hline 303.15 & 3249.99 & 1.19 & 3043.91 & 6.34 \\
\hline 313.15 & 1349.48 & 1.64 & 1349.48 & 0.00 \\
\hline 323.15 & 614.12 & 1.99 & 644.60 & 4.96 \\
\hline 333.15 & 313.86 & 3.03 & 328.51 & 4.67 \\
\hline 343.15 & 168.23 & 2.78 & 177.17 & 5.31 \\
\hline 353.15 & 100.44 & 3.31 & 100.42 & 0.02 \\
\hline 363.15 & 64.85 & 2.69 & 59.48 & 8.27 \\
\hline \multicolumn{5}{|c|}{$\left[\mathrm{P}_{44410}\right] \mathrm{Cl}$} \\
\hline 293.15 & 6802.34 & 4.32 & 6765.87 & 0.54 \\
\hline 303.15 & 2742.77 & 6.41 & 2633.04 & 4.00 \\
\hline 313.15 & 1143.27 & 2.79 & 1149.58 & 0.55 \\
\hline 323.15 & 552.03 & 4.95 & 552.03 & 0.00 \\
\hline 333.15 & 291.05 & 4.43 & 287.07 & 1.37 \\
\hline 343.15 & 157.37 & 1.62 & 159.69 & 1.47 \\
\hline 353.15 & 94.09 & 2.81 & 94.08 & 0.00 \\
\hline 363.15 & 61.43 & 2.99 & 58.24 & 5.20 \\
\hline \multicolumn{5}{|c|}{$\left[\mathrm{P}_{44412}\right] \mathrm{Cl}$} \\
\hline 293.15 & - & - & - & - \\
\hline 303.15 & 1439.04 & 4.15 & 1429.76 & 0.64 \\
\hline 313.15 & 674.30 & 4.21 & 674.94 & 0.09 \\
\hline 323.15 & 342.50 & 1.91 & 345.98 & 1.02 \\
\hline 333.15 & 189.05 & 2.49 & 190.13 & 0.57 \\
\hline 343.15 & 110.86 & 3.93 & 110.86 & 0.00 \\
\hline 353.15 & 73.25 & 2.84 & 68.01 & 7.15 \\
\hline 363.15 & 48.50 & 2.30 & 43.60 & 10.12 \\
\hline
\end{tabular}

Table 12 Correlation parameters of the VFT equation, Eq.11, with the 10 deviations of the fit for the viscosity of $\left[\mathrm{P}_{444}\right] \mathrm{Cl}$ as a function of temperature, determined from experimental values in the range $T=$ 293.15 to $T=363.15 \mathrm{~K}$.

\begin{tabular}{ccccccc}
\hline $\boldsymbol{n}$ & $\boldsymbol{A}$ & $\boldsymbol{B} / \mathbf{K}$ & $\boldsymbol{T}_{\mathbf{0}} / \mathbf{K}$ & $\boldsymbol{B} / \boldsymbol{T}_{\mathbf{0}}$ & $\mathbf{A A D} / \boldsymbol{\%}$ & $\mathbf{M D} / \boldsymbol{\%}$ \\
\hline $\mathbf{1}$ & -12.38 & 2000.00 & 159.98 & 12.50 & 2.4 & 3.9 \\
$\mathbf{6}$ & -12.97 & 2096.43 & 158.56 & 13.22 & 1.9 & 6.0 \\
$\mathbf{8}$ & -15.82 & 3354.43 & 105.02 & 31.94 & 4.1 & 8.3 \\
$\mathbf{1 0}$ & -12.63 & 2096.27 & 149.03 & 14.07 & 1.6 & 5.2 \\
$\mathbf{1 2}$ & -12.57 & 2095.86 & 140.98 & 14.87 & 2.8 & 10.1 \\
\hline
\end{tabular}

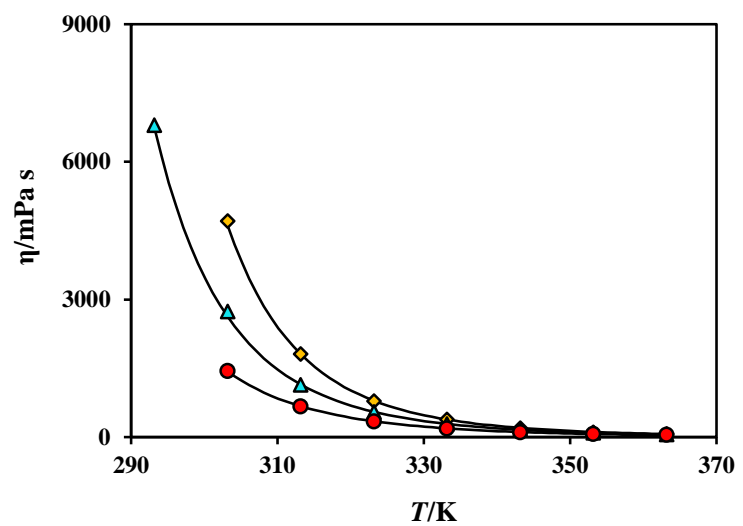

15 Fig. 25 Experimental viscosities as a function of temperature: $\left[\mathrm{P}_{4446}\right] \mathrm{Cl}$ $(\diamond),\left[\mathrm{P}_{44410}\right] \mathrm{Cl}(\Delta)$ and $\left[\mathrm{P}_{44412}\right] \mathrm{Cl}(\bullet)$ fitted into VFT equation, Eq. 11. Fits are represented by solid lines.

The experimental viscosity data are plotted against data calculated from Eq. 10 with the fitted data in Table 12, 20 represented in Figure 26; excellent agreement is revealed by the fit in Eq. 12

$$
\begin{array}{r}
\ln \left(\eta_{\text {cal }}\right)=(0.9974 \pm 0.0032) \ln \left(\eta_{\exp }\right) \\
\left(R^{2}=0.9995 \text { at a } 95 \% \text { of confidence }\right)
\end{array}
$$

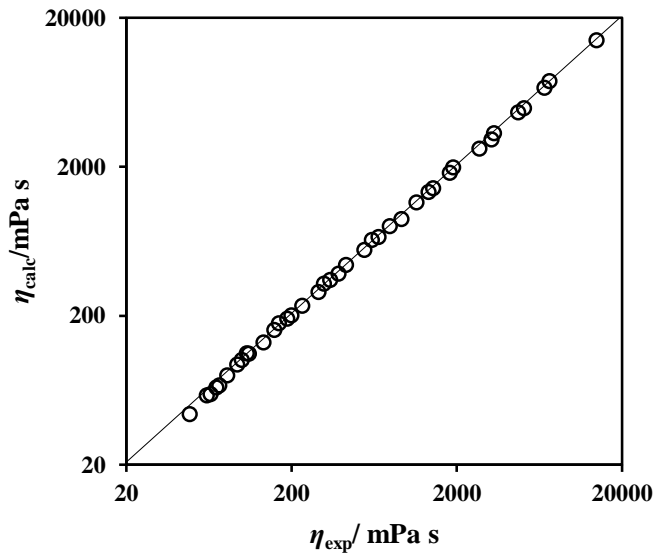

Fig. 26 Linear relationship between $\eta_{\text {exp }}$ and $\eta_{\text {cal }}$ using VFT equation, Eq. 11

Relative deviations between the calculated and the experimental viscosity data are presented in Table $\mathbf{1 1}$ along with experimental 30 viscosity values over a wide range of temperatures (293.15$363.15 K)$.

\section{Conclusions}

The series of ionic liquids presented here are all hydrophilic and present an interesting contrast with hydrophobic $\left[\mathrm{P}_{88}{ }_{8 n}\right] \mathrm{Cl}$. Of 35 particular interest is the crystal structure of $\left[\mathrm{P}_{4443}\right] \mathrm{Cl}$ which allows a comparison to be made with its tetraalkylammonium analogues. The combination of electrostatic attraction, hydrogen bonding and steric repulsion leads to a delicate balance between these forces. The shorter nitrogen carbon bonds of the 40 tetraalkylammonium structures leads to a sterically compressed "shell" of methylene groups, which prevent the close approach of the chloride ion that might have been expected from a facile 
consideration of the size of the nitrogen atom. In contrast, the larger phosphorus atom and longer phosphorus carbon bonds leads to a more open structure, permitting the chloride ion to approach closer to the centre of the cation. Although 5 counter-intuitive, the observed structures lead to an intellectually satisfying interpretation of some of the contrasting properties of tetraalkylammonium and tetraalkylphosphonium ionic liquids.

\section{Acknowledgements}

This work was funded by Cytec Canada, Inc. G.A. would like to 10 thank Dr. Douglas Harris (Cytec) for fruitful comments and advices at the beginning of this work; Prof. Chris Strauss, Dr. Markus Fanselow and Dr. Giulia Fiorani for microvawe assistance and helpful guidance, and Prof. P.R. Raithby for the Xray diffraction data collection. L.P.N.R. thanks Fundação para 15 a Ciência e Tecnologia for support under grants PTDC/QUIQUI/101794/2008 and PTDC/QUI/71331/2006.

\section{Notes and references}

${ }^{a}$ The QUILL Centre, The Queen's University of Belfast, Stranmillis Road, 20 Belfast, UK BT9 5AG.

${ }^{b}$ Current address: Department of Chemistry, Indian Institute of

Technology Madras, Chennai, India, 600036.

c Instituto de Tecnologia Química e Biológica, www.itqb.unl.pt,

Universidade Nova de Lisboa, Oeiras, Portugal, 2780-901.

25 Cytec Canada Inc, 9061 Garner Rd., Niagara Falls, Ontario, Canada L2E 6 S5.

${ }^{d}$ Cytec Canada Inc, 9061 Garner Rd., Niagara Falls, Ontario, Canada L2E 6 S5.

$\dagger$ Electronic Supplementary Information (ESI) available: [details of any 30 supplementary information available should be included here]. See DOI: $10.1039 / \mathrm{b} 000000 \mathrm{x} /$

1. K. J. Fraser and D. R. MacFarlane, Aust. J. Chem., 2009, 62, 309321.

35 2. R. E. Del Sesto, C. Corley, A. Robertson and J. S. Wilkes, J. Organomet. Chem., 2005, 690, 2536-2542.

3. K. Tsunashima and M. Sugiya, Electrochemistry, 2007, 75, 734-736.

4. M. Matsumiya, S. Suda, K. Tsunashima, M. Sugiya, S. Kishioka and H. Matsuura, J. Electroanal. Chem., 2008, 622, 129-135.

40 5. J. Pernak, F. Stefaniak and J. Weglewski, Eur. J. Org. Chem., 2005, 650-652.

6. J. A. Vega, J. F. Zhou and P. A. Kohl, J. Electrochem. Soc., 2009, 156, A253-A259.

7. C. J. Bradaric, A. Downard, C. Kennedy, A. J. Robertson and Y. H. 45 Zhou, Green Chem., 2003, 5, 143-152.

8. S. A. Chowdhury, J. L. Scott and D. R. MacFarlane, Pure Appl. Chem., 2008, 80, 1325-1335.

9. M. G. Freire, P. J. Carvalho, R. L. Gardas, L. Santos, I. M. Marrucho and J. A. P. Coutinho, J. Chem. Eng. Data, 2008, 53, 2378502382.

10. J. M. S. S. Esperança, H. J. R. Guedes, M. Blesic and L. P. N. Rebelo, J. Chem. Eng. Data, 2006, 51, 237-242.

11. G. Adamová, R. L. Gardas, L. P. N. Rebelo, A. J. Robertson and K. R. Seddon, J. Chem. Soc. Dalton Trans., submitted.

55 12. G. Adamová, R. L. Gardas, L. P. N. Rebelo, A. J. Robertson and K. R. Seddon, J. Chem. Soc. Dalton Trans., manuscript in preparation.
13. R. L. Gardas, R. Ge, P. Goodrich, C. Hardacre, A. Hussain and D. W. Rooney, J. Chem. Eng. Data, 2010, 55, 1505-1515.

60 14. K. Fukumoto and H. Ohno, Chem. Commun., 2006, 3081-3083.

15. J. Kagimoto, K. Fukumoto and H. Ohno, Chem. Commun., 2006, 2254-2256.

16. J. F. Knifton, Journal of Molecular Catalysis, 1987, 43, 65-78.

17. US 4265828, (Texaco Inc., USA) Pat., 1981.

65 18. US 4339545, (Texaco Inc., USA) Pat., 1982.

19. US 4332914, (Texaco Inc., USA) Pat., 1982.

20. US 4362822, (Texaco Inc., USA) Pat., 1982.

21. US 4315994, (Texaco Inc., USA) Pat., 1982.

22. US 4518715, (Texaco Inc., USA) Pat., 1985.

70 23. US 4605677, (Texaco Inc., USA) Pat., 1986.

24. US 4622343, (Texaco Inc., USA) Pat., 1986.

25. US 4366259, (Texaco Inc., USA) Pat., 1982.

26. US 4332915, (Texaco Inc., USA) Pat., 1982.

27. US 4835143 Pat., 1989.

75 28. US 4874526 Pat., 1988.

29. M. Petkovic, D. Hartmann, G. Adamová, K. R. Seddon, L. P. N. Rebelo and C. Silva Pereira, manuscript in preparation.

30. G. M. Sheldrick, Acta Crystallogr. A, 2008, 64, 112-122.

31. F. H. Allen, Acta Crystallogr. B, 2002, 58, 380-388.

80 32. F. H. Allen and W. D. S. Motherwell, Acta Crystallogr. B, 2002, 58, 407-422.

33. J. D. Holbrey, R. D. Rogers, S. S. Shukla and C. D. Wilfred, Green Chem., 2010, 12, 407-413.

34. M. M. Rauhut, H. A. Currier, A. M. Semsel and V. P. Wystrach, J. 85 Am. Chem. Soc., 1961, 26, 5138-5145.

35. W. Markownikoff, Justus Liebigs Ann. Chem., 1870, 153, 228-259.

36. , 2011.

37. , Searches on the CSD for any phosphonium cations where the phosphorus atoms is bonded to four carbon atoms; 3774 hits $90 \quad$ found

38. A. Bondi, J. Phys. Chem., 1964, 68, 444-451.

39. J. A. van der Berg and K. R. Seddon, Cryst. Growth Des., 2003, 3, 643-661.

40. Q. Wang, A. Habenschuss, A. Xenopoulos and B. Wunderlich, Mol.

$95 \quad$ Cryst. Liq. Cryst., 1995, 264, 115-129.

41. W. Prukala, B. Marciniec and M. Kubicki, Acta Crystallogr. E, 2007, 63, o1464-o1466.

42. S. H. Hong, A. G. Wenzel, T. T. Salguero, M. W. Day and R. H. Grubbs, J. Am. Chem. Soc., 2007, 129, 7961-7968.

100 43. G. Margraf, H. W. Lerner and M. Bolte, Acta Crystallogr. E, 2002, 58, 0546-0547.

44. A. Kornath, F. Neumann and H. Oberhammer, Inorg. Chem., 2003, 42, 2894-2901.

45. D. J. Abdallah, R. E. Bachman, J. Perlstein and R. G. Weiss, J. Phys. 105 Chem. B, 1999, 103, 9269-9278.

46. U. Monkowius, N. W. Mitzel, A. Schier and H. Schmidbaur, J. Am. Chem. Soc., 2002, 124, 6126-6132.

47. N. D. Gomelya, N. G. Feshchenko, A. N. Chernega, M. Y. Antipin, Y. T. Struchkov and I. E. Boldeskul, Zh. Obshch. Khim., 1985, 55, 1733-1738.

110

48. B. Ziemer and F. Krech, private communication to the CSD, 2003.

49. R. J. Staples, Z. Krist.-New Cryst. Struct., 1999, 214, 231-232. 
50. Y. Yan, J. T. Mague and J. P. Donahue, Acta Crystallogr. E, 2009, 65, 01491-U01779.

51. P. M. Dean, J. M. Pringle and D. R. MacFarlane, Acta Crystallogr. E, 2008, 64, O637-U1540.

5 52. G. Laus, G. Bentivoglio, V. Kahlenberg, U. J. Griesser, H. Schottenberger and G. Nauer, Crystengcomm, 2008, 10, 748752.

53. A. Bondi, J. Phys. Chem., 1964, 68, 441-451.

54. J. A. van den Berg and K. R. Seddon, Cryst. Growth Des., 2003, 3, $10 \quad 643-661$.

55. U. Monkowius, S. Nogai and H. Schmidbaur, Z. Naturforsch. B, 2004, 59, 259-263.

56. P. M. Dean, B. R. Clare, V. Armel, J. M. Pringle, C. M. Forsyth, M. Forsyth and D. R. MacFarlane, Aust. J. Chem., 2009, 62, 334-

15 340.

57. A. Getsis and A. V. Mudring, Zeitschrift Fur Anorganische Und Allgemeine Chemie, 2009, 635, 2214-2221.

58. D. J. Evans and D. L. Hughes, Acta Crystallogr. C, 1990, 46, 14521454.

20 59. P.Hunt, personal communication edn., personal communication, 2009.

60. K. Tsunashima, S. Kodama, M. Sugiya and Y. Kunugi, Electrochim. Acta, 2010, 56, 762-766.

61. C. F. Ye and J. M. Shreeve, J. Phys. Chem. A, 2007, 111, 1456-1461.

25 62. R. L. Gardas and J. A. P. Coutinho, Fluid Phase Equilib., 2008, 263, 26-32.

63. R. L. Gardas, M. G. Freire, P. J. Carvalho, I. M. Marrucho, I. M. A. Fonseca, A. G. M. Ferreira and J. A. P. Coutinho, J. Chem. Eng. Data, 2007, 52, 80-88.

30 64. R. L. Gardas, M. G. Freire, P. J. Carvalho, I. M. Marrucho, I. M. A. Fonseca, A. G. M. Ferreira and J. A. P. Coutinho, J. Chem. Eng. Data, 2007, 52, 1881-1888.

65. H. D. B. Jenkins, H. K. Roobottom, J. Passmore and L. Glasser, Inorg. Chem., 1999, 38, 3609-3620.

35 66. M. Tariq, A. P. Serro, J. L. Mata, B. Saramago, J. M. S. S. Esperança, J. N. C. Lopes and L. P. N. Rebelo, Fluid Phase Equilib., 2010, 294, 131-138.

67. M. Tariq, P. A. S. Forte, M. F. C. Gomes, J. N. C. Lopes and L. P. N. Rebelo, J. Chem. Thermodyn., 2009, 41, 790-798.

40 68. L. I. N. Tomé, R. L. Gardas, P. R. Carvalho, M. J. Pastoriza-Gallego, M. M. Piñeiro and J. A. P. Coutinho, J. Chem. Eng. Data, 2011, doi.org/10.1021/je101232g.

69. G. Adamová, J. N. C. Lopes, L. P. N. Rebelo, A. J. Robertson and K. R. Seddon, Chem. Sci., manuscript in preparation.

45 70. S. A. Forsyth, J. M. Pringle and D. R. MacFarlane, Aust. J. Chem., 2004, 57, 113-119.

71. K. R. Seddon, A. Stark and M. J. Torres, Pure and Applied Chemistry, 2000, 72, 2275-2287.

72. K. R. Seddon, A. Stark and M. J. Torres, in Clean Solvents $50 \quad$ Alternative Media for Chemical Reactions and Processing, eds. M. A. Abraham and L. Moens, Amer Chemical Soc, Washington, 2002, vol. 819, pp. 34-49.

73. A. A. Fannin, D. A. Floreani, L. A. King, J. S. Landers, B. J. Piersma, D. J. Stech, R. L. Vaughn, J. S. Wilkes and J. L. Williams, J. Phys. Chem., 1984, 88, 2614-2621. 